Photoelectron spectroscopic study of the E\#e Jahn-Teller effect in the presence of a tunable spin-orbit interaction. III. Two-state excitonic model accounting for observed trends in the (X)over-tilde(2)E ground state of $\mathrm{CH} 3 \mathrm{X}+(\mathrm{X}=\mathrm{F}, \mathrm{Cl}$, $\mathrm{Br}, \mathrm{I})$ and $\mathrm{CH} 3 \mathrm{Y}(\mathrm{Y}=\mathrm{O}, \mathrm{S})$

Journal Article

Author(s):

Grütter, Michel; Qian, Ximei; Merkt, Frédéric

Publication date:

2012-08-28

Permanent link:

https://doi.org/10.3929/ethz-a-010780487

Rights / license:

In Copyright - Non-Commercial Use Permitted 
Originally published in:

The Journal of Chemical Physics 137(8), https://doi.org/10.1063/1.4745002

\section{Funding acknowledgement:}

135342 - Rydberg states, VUV laser spectroscopy and photoionization dynamics (SNF) 
This article may be downloaded for personal use only. Any other use requires prior permission of the author and AIP Publishing.

The following article appeared in J. Chem. Phys. 137, 084313 (2012) and may be found at http://dx.doi.org/10.1063/1.4745002. 


\section{AIP | The Journal of Chemical Physics}

Photoelectron spectroscopic study of the $E \otimes e$ Jahn-Teller effect in the presence of a tunable spin-orbit interaction. III. Two-state excitonic model accounting for observed trends in the $\bar{X} 2 \mathrm{E}$ ground state of $\mathrm{CH} 3 X+(X=F, C l, B r, I)$ and $\mathrm{CH} 3 Y(Y=0, S)$ M. Grütter, X. Qian, and F. Merkt

Citation: The Journal of Chemical Physics 137, 084313 (2012); doi: 10.1063/1.4745002

View online: http://dx.doi.org/10.1063/1.4745002

View Table of Contents: http://scitation.aip.org/content/aip/journal/jcp/137/8?ver=pdfcov Published by the AIP Publishing

\section{Articles you may be interested in}

Jahn-Teller effect in $\mathrm{CH} 2 \mathrm{DO} / \mathrm{CHD} 2 \mathrm{O}$ ( $\mathrm{X} 2 \mathrm{E}$ ): Vibronic coupling of all vibrational modes J. Chem. Phys. 138, 244309 (2013); 10.1063/1.4811517

The spectroscopic characterization of the methoxy radical. III. Rotationally resolved $A^{\sim} 2 \mathrm{~A} 1-\mathrm{X} 2 \mathrm{E}$ electronic and $\mathrm{X} 2 \mathrm{E}$ submillimeter wave spectra of partially deuterated $\mathrm{CH} 2 \mathrm{DO}$ and $\mathrm{CHD} 2 \mathrm{O}$ radicals J. Chem. Phys. 135, 094310 (2011); 10.1063/1.3615724

Photoelectron spectroscopic study of the $\mathrm{E} \otimes \mathrm{e}$ Jahn-Teller effect in the presence of a tunable spin-orbit interaction. I. Photoionization dynamics of methyl iodide and rotational fine structure of $\mathrm{CH} 3 \mathrm{I}+$ and $\mathrm{CD} 3 \mathrm{I}+$ J. Chem. Phys. 134, 054308 (2011); 10.1063/1.3547548

The photoelectron spectrum of the isopropoxide anion: Nonadiabatic effects due to conical intersections and the spin-orbit interaction

J. Chem. Phys. 130, 154312 (2009); 10.1063/1.3109992

Cavity ringdown spectrum of the forbidden $A^{\sim} E E^{\prime \prime} 2 \leftarrow X A 2^{\prime} 2$ transition of NO 3 : Evidence for static Jahn-Teller distortion in the $A^{\sim}$ state

J. Chem. Phys. 122, 224305 (2005); 10.1063/1.1897364

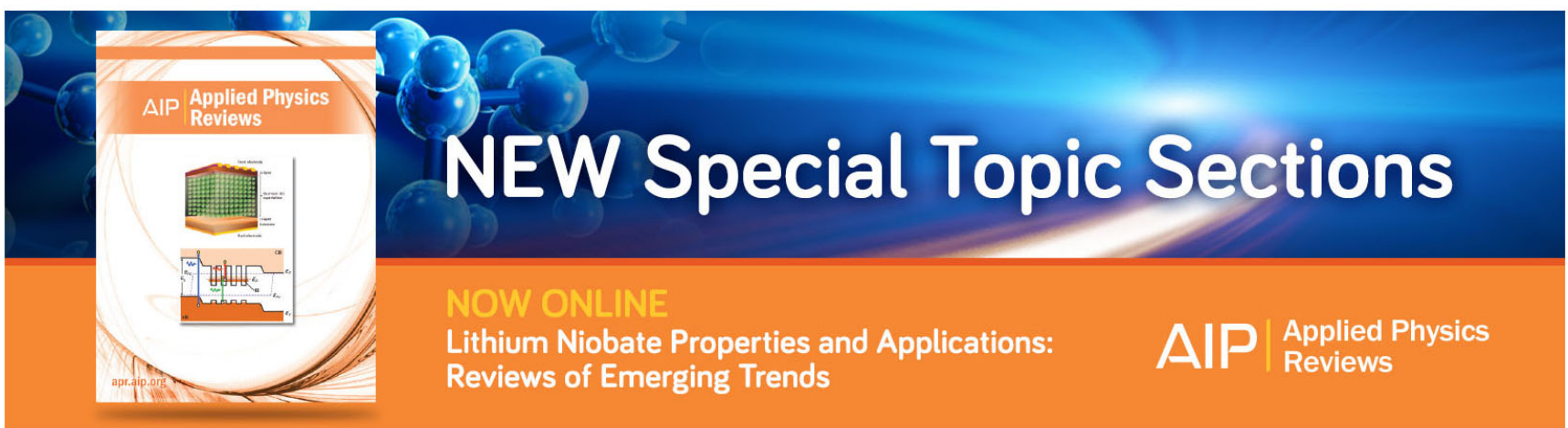




\title{
Photoelectron spectroscopic study of the E $\otimes$ e Jahn-Teller effect in the presence of a tunable spin-orbit interaction. III. Two-state excitonic model accounting for observed trends in the $\tilde{\mathrm{X}}^{2} \mathrm{E}$ ground state of $\mathrm{CH}_{3} \mathrm{X}^{+}(\mathrm{X}=\mathrm{F}, \mathrm{Cl}, \mathrm{Br}, \mathrm{I})$ and $\mathrm{CH}_{3} \mathrm{Y}(\mathrm{Y}=\mathrm{O}, \mathrm{S})$
}

\author{
M. Grütter, X. Qian, and F. Merkt \\ Laboratorium für Physikalische Chemie, ETH Zürich, CH-8093 Zurich, Switzerland
}

(Received 25 May 2012; accepted 20 July 2012; published online 29 August 2012)

\begin{abstract}
Open-shell molecules in doubly degenerate ${ }^{2} \mathrm{E}$ electronic states are subject to the $\mathrm{E} \otimes \mathrm{e}$ Jahn-Teller effect and spin-orbit interactions. The rotational structure of the ground vibrational level of the $\tilde{\mathrm{X}}^{+}$ ${ }^{2} \mathrm{E}$ ground state of $\mathrm{CH}_{3} \mathrm{~F}^{+}$has been observed by high-resolution photoelectron spectroscopy. In contrast to what is observed in other members of the isoelectronic families $\mathrm{CH}_{3} \mathrm{X}^{+}(\mathrm{X}=\mathrm{Cl}, \mathrm{Br}, \mathrm{I})$ and $\mathrm{CH}_{3} \mathrm{Y}(\mathrm{Y}=\mathrm{O}, \mathrm{S})$, the spin-orbit interaction does not lead to a splitting of the ground state of $\mathrm{CH}_{3} \mathrm{~F}^{+}$. Observed trends in the spectra of the $\tilde{\mathrm{X}}^{2} \mathrm{E}$ ground states of these molecules are summarized. Whereas certain trends, such as the reduction of the observable effects of the Jahn-Teller interactions and the increase of the spin-orbit splitting with increasing nuclear charge of $\mathrm{X}$ and $\mathrm{Y}$ are easily understood, other trends are more difficult to explain, such as the much reduced spin-orbit splitting in $\mathrm{CH}_{3} \mathrm{~F}^{+}$ compared to $\mathrm{CH}_{3} \mathrm{O}$. A simple two-state excitonic model is used to account for the trends observed within the series of the methyl-halide radical cations and also the similarities and differences between $\mathrm{CH}_{3} \mathrm{~F}^{+}$and the isoelectronic $\mathrm{CH}_{3} \mathrm{O}$ radical. Within this model, the electron hole in the ${ }^{2} \mathrm{E}$ ground states of $\mathrm{CH}_{3} \mathrm{X}^{+}$and $\mathrm{CH}_{3} \mathrm{Y}$ is described in terms of contributions from the halogenic (or chalcogenic) $\mathrm{p}_{x, y}$ orbitals and the pyramidal-methylic (e) orbitals. This model enables a global, semi-quantitative description of the combined effects of the Jahn-Teller and spin-orbit interactions in these molecules and also a simple interpretation of the spin-orbit-coupling reduction factor $\zeta_{\mathrm{e}}$. (C) 2012 American Institute of Physics. [http://dx.doi.org/10.1063/1.4745002]
\end{abstract}

\section{INTRODUCTION}

The Jahn-Teller effect and spin-orbit coupling occur jointly in orbitally degenerate states of symmetric nonlinear polyatomic molecules and strongly influence their structural, spectral, and dynamical properties. ${ }^{1-5}$ In the literature, the Jahn-Teller effect and spin-orbit interaction are often described as being in competition: ${ }^{2-4,6-8} \mathrm{~A}$ large spin-orbit interaction tends to quench the Jahn-Teller effect, and a strong Jahn-Teller effect reduces the magnitude of the spin-orbit splittings. The latter effect is known as the Ham reduction effect. 3,6

The He I photoelectron spectra (PES) of $\mathrm{CH}_{3} \mathrm{~F}, \mathrm{CH}_{3} \mathrm{Cl}$, $\mathrm{CH}_{3} \mathrm{Br}$, and $\mathrm{CH}_{3} \mathrm{I}$ (reproduced in Fig. 1 using data from Ref. 7) represent a nice illustration of these effects: The photoelectron spectra of $\mathrm{CH}_{3} \mathrm{Br}$ and $\mathrm{CH}_{3} \mathrm{I}$ consist essentially of two sharp lines separated by an "atomic-like" spin-orbit splitting. The absence of an extended vibrational progression indicates that no significant changes in the molecular structure take place upon ionization and that the distortion induced by the Jahn-Teller effect is minimal. The spin-orbit interaction appears to have quenched the Jahn-Teller effect.

The photoelectron spectrum of $\mathrm{CH}_{3} \mathrm{~F}$, on the other hand, consists of extended vibrational progressions which betray a significant change of the molecular structure upon ionization, indicative of a significant Jahn-Teller effect. Moreover, the absence of recognizable spin-orbit doublets further sug- gests that the spin-orbit interaction has been quenched by the Jahn-Teller effect in the $\tilde{\mathrm{X}}^{+2} \mathrm{E}$ ground state of $\mathrm{CH}_{3} \mathrm{~F}^{+}$. The resolution of the He I photoelectron spectra of $\mathrm{CH}_{3} \mathrm{~F}$ is, however, not sufficient to draw these conclusions with certainty. The photoelectron spectrum of $\mathrm{CH}_{3} \mathrm{Cl}$ appears to take an intermediate position between these two limiting cases. Studies of the $\tilde{\mathrm{A}}^{2} \mathrm{~A}_{1}-\tilde{\mathrm{X}}^{2} \mathrm{E}$ band system of $\mathrm{CH}_{3} \mathrm{O}$ and $\mathrm{CH}_{3} \mathrm{~S}$ by Hirota and co-workers ${ }^{9-11}$ and Miller and co-workers ${ }^{2,11-14}$ indicate a similar overall behavior of these isoelectronic molecules.

The investigation of the photoelectron spectra of $\mathrm{CH}_{3} \mathrm{I}$ and $\mathrm{CH}_{3} \mathrm{Cl}$ at high resolution described in the first articles of this series, ${ }^{15,16}$ together with the rotationally resolved photoelectron spectrum of the origin band of $\mathrm{CH}_{3} \mathrm{~F}$ presented in Sec. II A of this article, provide additional information on the competition of the Jahn-Teller effect and spin-orbit coupling in these systems. From these works and a recent study of the $\tilde{\mathrm{X}}^{+2} \mathrm{E}$ ground state of $\mathrm{CH}_{3} \mathrm{Cl}^{+}$by Shao et al. ${ }^{17}$ which combines high-resolution photoelectron spectroscopy with a high-level diabatic Jahn-Teller calculation, precise values of spin-orbit splittings have been extracted and the analysis of the rotational structure has enabled the characterization of the Jahn-Teller effect along the low-frequency modes $v_{5}$ and $v_{6}$. This information, while overall compatible with the general trends described above, also reveals inconsistencies, and uncovers behavior that is not as easily explainable as the 

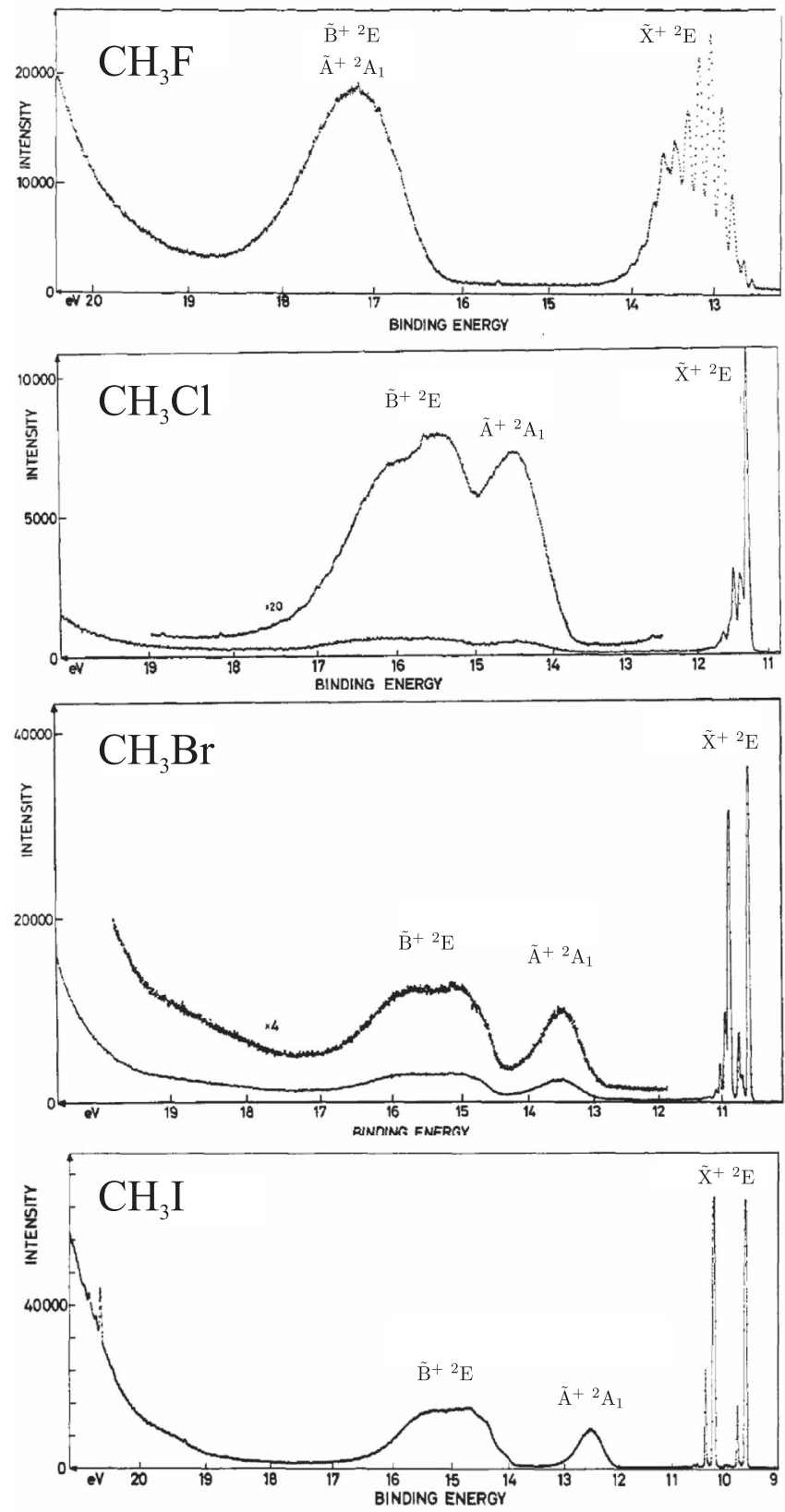

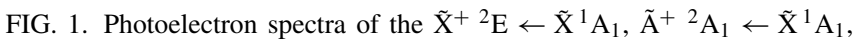
and $\tilde{\mathrm{B}}^{+}{ }^{2} \mathrm{E} \leftarrow \tilde{\mathrm{X}}^{1} \mathrm{~A}_{1}$ transitions of $\mathrm{CH}_{3} \mathrm{~F}, \mathrm{CH}_{3} \mathrm{Cl}, \mathrm{CH}_{3} \mathrm{Br}$, and $\mathrm{CH}_{3} \mathrm{I}$ (top to bottom panels) recorded by Karlsson and co-workers. ${ }^{7}$ Adapted from Ref. 7.

overall patterns of the $\mathrm{He}$ I spectra: A much stronger reduction of the spin-orbit splitting is observed in $\mathrm{CH}_{3} \mathrm{~F}^{+}$than in $\mathrm{CH}_{3} \mathrm{O}$, although the Jahn-Teller effect is of similar strength to that observed in $\mathrm{CH}_{3} \mathrm{O}$; the dominant Jahn-Teller-active mode is $v_{6}$ in $\mathrm{CH}_{3} \mathrm{O}, \mathrm{CH}_{3} \mathrm{~S}, \mathrm{CH}_{3} \mathrm{Cl}^{+}$, and $\mathrm{CH}_{3} \mathrm{I}^{+}$, but appears to be $v_{5}$ in $\mathrm{CH}_{3} \mathrm{~F}^{+}$; ${ }^{18-20}$ finally, the $\mathrm{E} \otimes \mathrm{e}$ Jahn-Teller effect in $\mathrm{CH}_{3} \mathrm{~F}^{+}$ might be weaker than what the extended progression of the $\mathrm{He}$ I spectrum indicates at first sight: The main progression in the spectrum might correspond to the $\mathrm{C}-\mathrm{F}$ stretching mode of $\mathrm{a}_{1}$ symmetry ${ }^{18-20}$ and does not distort the molecule away from $\mathrm{C}_{3 \mathrm{v}}$ symmetry. The complete quenching of the spin-orbit coupling therefore cannot be attributed solely to the Jahn-Teller effect.
As explained in Refs. 15 and 16, the observed spin-orbit splitting can be expressed in first approximation as $a \zeta_{\mathrm{e}} d_{j, v}$, where $a$ corresponds to an atomic-like spin-orbit coupling constant, $\left|d_{j, v}\right|(\in[0,1])$ to the reduction factor originating from the Jahn-Teller effect, and $\zeta_{\mathrm{e}}(\in[0,1])$ to an electronic reduction factor. $\zeta_{\mathrm{e}}$ was introduced by $\mathrm{McClure}^{21}$ to explain the absence of spin-orbit splittings in triplet states of aromatic hydrocarbons. In linear molecules following Hund's angularmomentum coupling case (a), the spin-orbit splittings arise from differences in the expectation values $a \Sigma \Lambda$ of the spinorbit operator, $\Sigma$ and $\Lambda$ being the quantum numbers associated with the projection of the electron spin and orbital angular momentum onto the internuclear axis, respectively. In a doubly degenerate (E) state of a polyatomic molecule, $\Lambda$ is no longer a good quantum number because of vibronic interactions and the reduced molecular symmetry; the projection of the orbital angular momentum onto the $z$ axis of the moleculefixed frame can be expressed as $\pm \zeta_{\mathrm{e}} . \zeta_{\mathrm{e}}$ is referred to as the expectation value of $L_{z}\left(\left\langle \pm\left|\hat{L}_{z}\right| \pm\right\rangle= \pm \zeta_{\mathrm{e}}\right)$ with respect to the two components $( \pm)$ of the degenerate $\mathrm{E}$ state ${ }^{22}$ and is sometimes thought of as arising from the off-axis atoms. ${ }^{1,21}$

A distinctive advantage of our high-resolution pulsedfield-ionization zero-kinetic-energy (PFI-ZEKE) photoelectron spectroscopic studies of the Jahn-Teller effect in the cations $\mathrm{CH}_{3} \mathrm{X}^{+}$over the previous studies by He I PES is the possibility to determine the effective vibronic Coriolis coupling parameter $\zeta_{\mathrm{ev}},{ }^{15,16}$ which in combination with the results from the vibronic analysis of the spectra of the $\tilde{\mathrm{X}}^{+2} \mathrm{E}$ ground states ${ }^{17-19}$ allows the determination of independent values for $d_{j, v}$ and $\zeta_{\mathrm{e}}$.

We present here a simple two-state "excitonic" model which provides an explanation for the strongly reduced value of $\zeta_{\mathrm{e}}$ in $\mathrm{CH}_{3} \mathrm{~F}^{+}$compared to $\mathrm{CH}_{3} \mathrm{Cl}^{+}, \mathrm{CH}_{3} \mathrm{Br}^{+}, \mathrm{CH}_{3} \mathrm{I}^{+}$, and in particular also to $\mathrm{CH}_{3} \mathrm{O}$ and $\mathrm{CH}_{3} \mathrm{~S}$. Despite its simplicity, the model also enables a coherent, semi-quantitative interpretation of the seemingly inconsistent trends observed experimentally and mentioned above.

The article is organized as follows: Section II presents new experimental results on the rotational structure of the $\tilde{\mathrm{X}}{ }^{2} \mathrm{E}$ ground state of $\mathrm{CH}_{3} \mathrm{~F}^{+}$and summarizes the main experimental observations made to date concerning the spin-orbit interaction and the Jahn-Teller effect in $\mathrm{CH}_{3} \mathrm{X}^{+}$ $(\mathrm{X}=\mathrm{F}, \mathrm{Cl}, \mathrm{Br}, \mathrm{I})$ and $\mathrm{CH}_{3} \mathrm{Y}(\mathrm{Y}=\mathrm{O}, \mathrm{S})$. The excitonic model used to interpret these observations is presented in Sec. III, where the predictions made with this model are compared to experimental data. The article ends with a summary of the main conclusions.

\section{SUMMARY OF OBSERVATIONS MADE ON THE SPIN-ORBIT INTERACTION AND THE JAHN-TELLER EFFECT IN MOLECULES OF THE TYPE $\mathrm{CH}_{3} \mathrm{X}^{+}(\mathrm{X}=\mathrm{F}, \mathrm{Cl}, \mathrm{Br}, \mathrm{I})$ AND $\mathrm{CH}_{3} \mathrm{Y}(\mathrm{Y}=\mathrm{O}, \mathrm{S})$}

The data presented in this section represent a compilation of results on the Jahn-Teller and spin-orbit interaction strengths in the $\tilde{X}^{+}{ }^{2} \mathrm{E}$ ground state of the methyl-halide cations and of the methoxy and thiomethoxy radicals. Conflicting assignments, and incompatible datasets were reported in the literature. Rather than presenting all data, a selection 
has been made of those we identified either as being most accurate or representative. The sources we considered include (i) studies of $\mathrm{CH}_{3} \mathrm{X}^{+}$by photoelectron, photoionization, and Rydberg spectroscopy, ${ }^{7,15-17,20,23-37}$ (ii) studies of $\mathrm{CH}_{3} \mathrm{Y}$ by optical spectroscopy, primarily by the groups of Miller, ${ }^{2}, 11-13$ and Hirota, ${ }^{9-11}$ and summarized in Ref. 2, (iii) ab initio quantum chemical calculations, ${ }^{17-19,38-40}$ (iv) vibronic coupling calculations carried out using $a b$ initio data, in some cases with parameters adjusted to experimental data, ${ }^{8,17-19,41,42}$ and (v) infrared spectroscopic data of $\mathrm{CH}_{3} \mathrm{X}^{+}$in matrices. ${ }^{38}$ Rotationally resolved data on the ground state of $\mathrm{CH}_{3} \mathrm{~F}^{+}$were not available and had to be measured and analyzed in the realm of this investigation, as described in Subsection II A.

\section{A. Rovibronic analysis of the PFI-ZEKE photoelectron spectrum of the origin band of the ${ }^{2} \mathrm{E}$ electronic ground state of $\mathrm{CH}_{3} \mathrm{~F}^{+}$}

The high-resolution photoelectron spectrum of $\mathrm{CH}_{3} \mathrm{~F}$ in the region of the first adiabatic ionization threshold was recorded by PFI-ZEKE photoelectron spectroscopy following single-photon excitation from the ground neutral state using a narrow-band vacuum-ultraviolet laser system. The laser system and the measurement and calibration procedures have been described in Refs. 16 and 43. The $\mathrm{CH}_{3} \mathrm{~F}$ gaseous sample (purity 99\%) was introduced into the spectrometer by means of a skimmed supersonic expansion characterized by a rotational temperature of $\approx 10 \mathrm{~K}$. The bandwidth of the laser system and the electric-field pulse sequence used to record the spectra resulted in a spectral resolution of $0.8 \mathrm{~cm}^{-1}$.

The origin band of the spectrum of the $\tilde{X}^{+} \leftarrow \tilde{X}$ ionizing transition of $\mathrm{CH}_{3} \mathrm{~F}$ is displayed in the top panel of Fig. 2. Unlike the spectra of the corresponding transitions of $\mathrm{CH}_{3} \mathrm{Cl}, \mathrm{CH}_{3} \mathrm{Br}$, and $\mathrm{CH}_{3} \mathrm{I}$, which all reveal a splitting of the origin band into two distinct, well-separated spin-orbit components, ${ }^{15,16,32}$ the spectrum of $\mathrm{CH}_{3} \mathrm{~F}$ consists of a single band with no noticeable spin-orbit splitting. Calculations (not shown) of the rovibronic structure of the ${ }^{2} \mathrm{E}$ origin of $\mathrm{CH}_{3} \mathrm{~F}^{+}$ were first performed using the effective Hamiltonian given by Eq. (10) of Ref. 15, and the selection rules appropriate to describe a Hund's-case-(b) to Hund's-case-(a) ionizing transition in the $\mathrm{C}_{3 \mathrm{v}}^{2}(\mathrm{M})$ molecular symmetry group. ${ }^{15}$ These calculations led to the conclusion that the spin-orbit splitting $a \zeta_{\mathrm{e}} d$ must be smaller than $2 \mathrm{~cm}^{-1}$ in order to correctly reproduce the observed rotational structure. Consequently, the rotational structure of the origin band of the photoelectron spectrum is more adequately described by treating $\mathrm{CH}_{3} \mathrm{~F}^{+}$as a Hund'scase-(b)-coupled symmetric-top molecular cation. The weakness of the spin-orbit interaction in the ${ }^{2} \mathrm{E}$ ground state of $\mathrm{CH}_{3} \mathrm{~F}^{+}$therefore allows a simplification of the spin-vibronic Hamiltonian $\hat{H}_{\text {eff }}$ and the spin-rotational Hamiltonian $\hat{H}_{\text {RSO }}$ used in Refs. 15 and 16 to analyze the photoelectron spectra of $\mathrm{CH}_{3} \mathrm{I}$ and $\mathrm{CH}_{3} \mathrm{Cl}$. It also necessitates the use of different rovibronic photoionization selection rules than those derived in Ref. 15.

The effective Hamiltonian $\left(\hat{H}_{\text {rot }}\right)$ describing the rotational structure of a symmetric-top molecule described by a Hund'scase-(b)-type angular momentum coupling, and subject to a
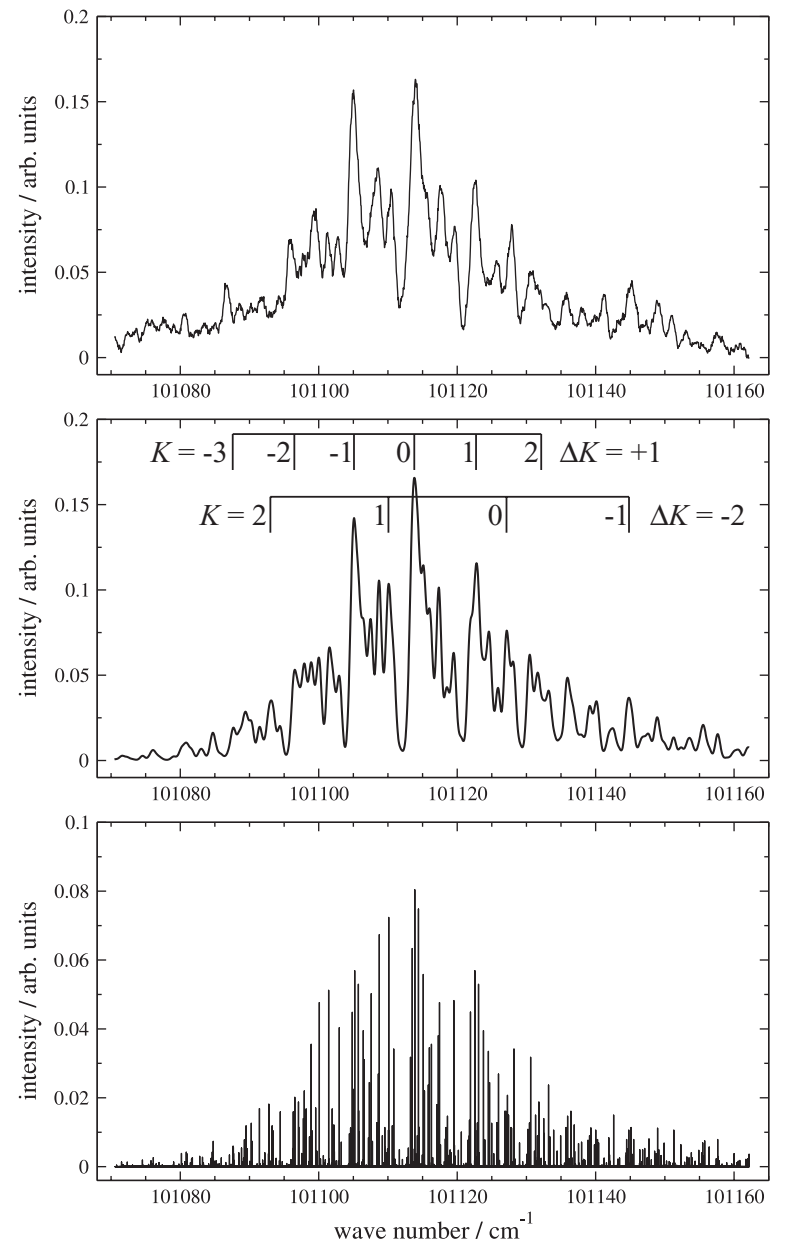

FIG. 2. High-resolution PFI-ZEKE photoelectron spectrum of the $\tilde{\mathrm{X}}^{+2} \mathrm{E} \leftarrow$ $\tilde{\mathrm{X}}^{1} \mathrm{~A}_{1}$ transition of $\mathrm{CH}_{3} \mathrm{~F}$ in the region of the vibronic ground state of $\mathrm{CH}_{3} \mathrm{~F}^{+}$ (top panel), and the corresponding calculation shown as stick spectrum (bottom panel) and after convolution with a Gaussian line profile with a FWHM of $0.8 \mathrm{~cm}^{-1}$ representing the instrumental linewidth (middle panel). The experimental spectrum has not been corrected for the field-induced shift $\left(\approx-0.84 \mathrm{~cm}^{-1}\right)$ of the ionization energies. The assignment bars label the most intense $\Delta N=0$ transitions of the dominant $\left(\Delta K=K^{+}-K=+1\right)$ and the minor $\left(\Delta K=K^{+}-K=-2\right)$ contributions to the vibronic wavefunction induced by the Jahn-Teller effect.

Jahn-Teller interaction is ${ }^{44}$

$$
\frac{\hbar^{2}}{h c} \hat{H}_{\text {rot }}=B \hat{\vec{N}}^{2}+(A-B) \hat{N}_{z}^{2}-2 A \hat{N}_{z} \hat{\pi}_{z}+A \hat{\pi}_{z}^{2} .
$$

In contrast to the effective spin-rotation Hamiltonian $\hat{H}_{\text {RSO }}$ used to describe the rotational structure of the spin-orbit-split vibronic levels of $\mathrm{CH}_{3} \mathrm{I}^{+}$and $\mathrm{CH}_{3} \mathrm{Cl}^{+}$given in Refs. 15 and $16, \hat{H}_{\text {rot }}$ is a diagonal matrix with eigenvalues

$$
\frac{E_{\mathrm{rot}}}{h c}=B N(N+1)+(A-B) K^{2}-2 A K \zeta_{\mathrm{ev}}+A \zeta_{\mathrm{ev}}^{2},
$$

where $\vec{N}=\vec{J}-\vec{S}$ and $K=P-\Sigma$ are the total angular momentum excluding electron spin and the quantum number associated with its projection onto the molecular $z$ axis, respectively.

Because $\left|a \zeta_{\mathrm{e}} d_{j, v}\right|$ is very small in the ${ }^{2} \mathrm{E}$ ground state of $\mathrm{CH}_{3} \mathrm{~F}^{+}$and the spin-orbit coupling constant of $\mathrm{HF}^{+}$is $a$ $=-242 \mathrm{~cm}^{-1},{ }^{45}$ the product $\zeta_{\mathrm{e}} d_{j, v}$ must be almost 0 . Consequently, $d_{j, v}$ cannot be determined from the analysis of the 
TABLE I. Allowed rovibronic transitions in a $\Gamma_{\mathrm{ev}}^{+}=\mathrm{E} \leftarrow \Gamma_{\mathrm{ev}}=\mathrm{A}_{1}$ photoionizing transition in the molecular symmetry group $\mathrm{C}_{3 \mathrm{v}}(\mathrm{M})$. The selection rules are the same for even- $\ell$ and odd $\ell$ photoelectron partial waves.

\begin{tabular}{llcc}
\hline \hline$\Gamma_{\mathrm{r}}=\Gamma_{\text {rve }}$ & & $\Gamma_{\mathrm{r}}^{+}$ & $\Gamma_{\mathrm{rve}}^{+}$ \\
\hline $\mathrm{A}_{1} / \mathrm{A}_{2}$ & $\rightarrow$ & $\mathrm{E}$ & $\mathrm{A}_{1} \oplus \mathrm{A}_{2} \oplus \mathrm{E}$ \\
$\mathrm{E}$ & $\rightarrow$ & $\mathrm{A}_{1} / \mathrm{A}_{2}$ & $\mathrm{E}$ \\
& $\rightarrow$ & $\mathrm{E}$ & $\mathrm{A}_{1} \oplus \mathrm{A}_{2} \oplus \mathrm{E}$ \\
\hline
\end{tabular}

rotational fine structure of individual vibronic bands, as was possible in the analysis of the vibronic ground state of the heavier methyl-halide cations.

Rovibronic photoionization selection rules for transitions from a Hund's-case(b)-type neutral parent molecule to a Hund's-case-(a)-type molecular cation subject to the simultaneous effects of a Jahn-Teller and spin-orbit interaction were derived in Ref. 15. The allowed rotational transitions obey the selection rule $\Delta P=\Omega^{\prime}$, where $\Omega^{\prime}=\Omega-\ell_{v}+\Sigma$ is the quantum number describing the projection of the total spinvibronic angular momentum excluding rotation. In the case of the photoionizing transition $\tilde{\mathrm{X}}^{+2} \mathrm{E} \leftarrow \tilde{\mathrm{X}}{ }^{1} \mathrm{~A}_{1}$ of $\mathrm{CH}_{3} \mathrm{~F}$, these rovibronic selection rules must be adapted to account for the

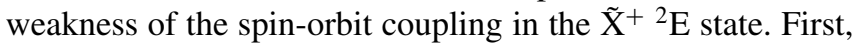
it is no longer necessary to use the $\mathrm{C}_{3 \mathrm{v}}^{2}(\mathrm{M})$ spin-double group and the rovibronic states of the cation are best described in the $\mathrm{C}_{3 \mathrm{v}}(\mathrm{M})$ group. Second, in the absence of spin-orbit coupling, the electron-spin projection quantum number $\Sigma$ is not defined any more. The selection rule changes to $\Delta K=\Lambda^{\prime}$, where $\Lambda^{\prime}=\Lambda-\ell_{v}$ defines the projection of the vibronic angular momentum onto the symmetry axis of the molecular cation. $\Lambda^{\prime}\left(=\Omega^{\prime}-\Sigma\right)$ takes the place of the total spin-vibronic angular momentum $\Omega^{\prime}$ used in the case of strong spin-orbit interaction. ${ }^{15,16}$

Because of the vibronic interaction induced by the $\mathrm{E} \otimes \mathrm{e}$ Jahn-Teller effect in the ${ }^{2} \mathrm{E}$ ground state of $\mathrm{CH}_{3} \mathrm{~F}^{+}$, the wavefunctions of the cationic vibronic levels consist of two contributions, a dominant one labeled by $\left|\Lambda_{a}^{\prime}\right\rangle$ and a minor one labeled by $\left|\Lambda_{b}^{\prime}\right\rangle$, in analogy to those labeled $\left|\Omega_{a}^{\prime}\right\rangle$ and $\left|\Omega_{b}^{\prime}\right\rangle$ in Ref. 16.

Table I summarizes the rovibronic photoionization symmetry selection rules which result from the general selection rules $^{46}$

$$
\begin{aligned}
& \Gamma_{\text {rve }} \otimes \Gamma_{\text {rve }}^{+} \supset \Gamma^{*} \text { for } \ell \text { even, } \\
& \Gamma_{\text {rve }} \otimes \Gamma_{\text {rve }}^{+} \supset \Gamma^{(\mathrm{s})} \text { for } \ell \text { odd, }
\end{aligned}
$$

and which were employed in the analysis of the PFI-ZEKE photoelectron spectra of the $\tilde{\mathrm{X}}^{+2} \mathrm{E} \leftarrow \tilde{\mathrm{X}}{ }^{1} \mathrm{~A}_{1}$ transition of $\mathrm{CH}_{3} \mathrm{~F}$. In Eq. (3), $\Gamma_{\text {rve }}$ and $\Gamma_{\text {rve }}^{+}$represent the rovibronic symmetries of the neutral and ionic states in the molecular symmetry group, $\Gamma^{(\mathrm{s})}$ is the totally symmetric representation, $\Gamma^{*}$ is the dipole-moment representation, and $\ell$ is the angular momentum quantum number of the photoelectron partial wave.

The spectrum calculated on the basis of Eqs. (1)-(3) after optimization of the relevant molecular constants is displayed in the bottom and middle panels of Fig. 2 as stick spectrum, and after convolution with a Gaussian linewidth of
$0.8 \mathrm{~cm}^{-1}$, respectively. The most intense spectral features correspond to partially resolved groups of $\Delta N=N^{+}-N=0$ transitions forming $\Delta K=K^{+}-K=\Lambda_{a}^{\prime}=+1$ branches. Weaker features correspond to $\Delta K=\Lambda_{b}^{\prime}=-2$ contributions from the minor component of the vibronic wave functions. The calculated positions of these features are indicated along the assignment bars in the middle panel of the figure. The best agreement with the experimental spectrum was reached by weighting the transition intensities with the ratio $(\Delta K=+1)$ : $(\Delta K=-2)=(5: 1)$. This ratio is the same as that determined for the electronic ground state of $\mathrm{CH}_{3} \mathrm{Cl}^{+},{ }^{16}$ which suggests that the Jahn-Teller effect in the ${ }^{2} \mathrm{E}$ ground state of $\mathrm{CH}_{3} \mathrm{~F}^{+}$is of comparable strength to that observed in the ${ }^{2} \mathrm{E}$ ground state of $\mathrm{CH}_{3} \mathrm{Cl}^{+}$. The rotational constants $A^{+}=5.28(8) \mathrm{cm}^{-1}$ and $B^{+}=0.94(3) \mathrm{cm}^{-1}$, and the vibronic Coriolis coefficient $\zeta_{\mathrm{ev}}$ $\leq 0.03$ (see Eq. (15) in Ref. 16) could be determined from the relative positions of the various $\left|N^{+}=N, K^{+}\right\rangle \leftarrow|N, K\rangle$ rovibronic transitions and the appearance of the two different branches $\left|N^{+}=N, K^{+}=K+1\right\rangle \leftarrow|N, K\rangle$ and $\mid N^{+}=N, K^{+}$ $=K-2\rangle \leftarrow|N, K\rangle$.

The orbital ionization model, ${ }^{47}$ which can be used to calculate the intensities of photoionizing transitions between Hund's-case-(b) ${ }^{48}$ or Hund's-case(a)-coupled ${ }^{15}$ states of symmetric-top molecules based on a single-center expansion of the highest occupied molecular orbital, cannot be used in the present case because it does not account for vibronic interactions in the neutral molecule or the cation (see Ref. 15). Consequently, the modeling of the relative intensities of the different $\Delta N=N^{+}-N$ branches must be carried out empirically, as discussed in Refs. 15 and 16. The calculated intensity distribution best matches the experimental PFI-ZEKE spectrum of $\mathrm{CH}_{3} \mathrm{~F}$ in the region of the vibronic origin of $\mathrm{CH}_{3} \mathrm{~F}^{+}$ when relative intensities of $10,6,2,2$, and 1 are assumed for the $\Delta N=0,|\Delta N|=1,|\Delta N|=2,|\Delta N|=3$, and $|\Delta N|$ $=4$ branches, respectively. The analysis of the intensity distribution of the spectrum of the ${ }^{2} \mathrm{E}$ state of $\mathrm{CH}_{3} \mathrm{~F}^{+}$requires the inclusion of non-zero transition intensities for $|\Delta N|=4$ branches, which were found to be of negligible importance in the case of the ${ }^{2} \mathrm{E}_{3 / 2}$ ground state of $\mathrm{CH}_{3} \mathrm{Cl}^{+}$(Ref. 16) and $\mathrm{CH}_{3} \mathrm{I}^{+} .^{15}$ From the selection rule $\Delta N_{\max }=\ell^{\max }+1, \ldots$, $-\ell^{\max }-1$ (Ref. 46) and the observation of $\left|\Delta N_{\max }\right|=4$, one must conclude that the single-center expansion of the (e) valence orbital of $\mathrm{CH}_{3} \mathrm{~F}^{+}$contains a significant $\mathrm{f}$ component $\left(\ell^{\max }=3\right)$.

These observations can be explained qualitatively by considering the orbital of the neutral molecule from which ionization occurs. In $\mathrm{CH}_{3} \mathrm{Cl}$ and $\mathrm{CH}_{3} \mathrm{I}$, the outermost molecular orbital can be well approximated by a lone pair located on the halogen atom. As will be discussed in Sec. III, the outermost valence orbital of $\mathrm{CH}_{3} \mathrm{~F}$ has a significant amplitude on the methyl group. This difference justifies the inclusion of higher orbital angular momentum components into the single-center expansion in the case of $\mathrm{CH}_{3} \mathrm{~F}$.

\section{B. Spin-orbit coupling}

The spin-orbit coupling constants $a \zeta_{\mathrm{e}} d_{j=1 / 2, v=0}$ of the $\mathrm{CH}_{3} \mathrm{X}^{+}$and $\mathrm{CH}_{3} \mathrm{Y}$ molecules considered here can be obtained directly from the spacings of the two spin-orbit components 
TABLE II. Spin-orbit coupling in the $\tilde{\mathrm{X}}^{+2} \mathrm{E}$ ground state of $\mathrm{CH}_{3} \mathrm{X}^{+}$and $\mathrm{CH}_{3} \mathrm{Y}$.

\begin{tabular}{|c|c|c|c|c|c|c|}
\hline & $\mathrm{CH}_{3} \mathrm{~F}^{+}$ & $\mathrm{CH}_{3} \mathrm{Cl}^{+}$ & $\mathrm{CH}_{3} \mathrm{Br}^{+}$ & $\mathrm{CH}_{3} \mathrm{I}^{+}$ & $\mathrm{CH}_{3} \mathrm{O}$ & $\mathrm{CH}_{3} \mathrm{~S}$ \\
\hline$a \zeta_{\mathrm{e}} d_{1 / 2,0}\left[\mathrm{~cm}^{-1}\right]$ & {$[-2,0]$} & $-217.5(2.0)^{\mathrm{a}}$ & $-2593(4)^{b}$ & $-5053(4)^{b}$ & $-61.974^{\mathrm{c}}$ & $-255.463^{\mathrm{c}}$ \\
\hline$a\left[\mathrm{~cm}^{-1}\right]$ & $-242^{\mathrm{d}}$ & $-663.6^{\mathrm{e}}$ & $-2662^{\mathrm{d}}$ & {$[-5310,-5180]^{\mathrm{f}}$} & $-139^{\mathrm{g}}$ & $-377^{\mathrm{g}}$ \\
\hline$\zeta_{\mathrm{e}} d_{1 / 2,0}$ & $\approx 0$ & $0.34^{\mathrm{a}}$ & 0.97 & $>0.97^{\mathrm{f}}$ & 0.45 & 0.676 \\
\hline$d_{1 / 2,0}$ & $\geq 0.07$ & 0.40 & $\ldots$ & {$[0.95,1.0]^{\mathrm{f}}$} & $0.57^{\mathrm{h}}$ & $0.82^{\mathrm{i}}$ \\
\hline$\zeta_{\mathrm{e}}$ & $<0.12$ & $0.86^{\mathrm{j}}$ & $\ldots$ & {$[0.97,1.0]^{\mathrm{f}}$} & $0.78^{\mathrm{h}}$ & $0.82^{\mathrm{i}}$ \\
\hline
\end{tabular}

a From Ref. 16.

${ }^{\mathrm{b}}$ From Ref. 32.

${ }^{\mathrm{c}}$ Value from Ref. 2.

${ }^{\mathrm{d}}$ Value of $a\left(\mathrm{HX}^{+}\right)$from Ref. 45

${ }^{\mathrm{e}}$ Value of $a\left(\mathrm{HCl}^{+}\right)$from Ref. 49

${ }^{\mathrm{f}}$ Value from analysis of PES of $\mathrm{CH}_{3} \mathrm{I}$ and $\mathrm{CD}_{3} \mathrm{I}^{15}$

${ }^{\mathrm{g}}$ Value of $a(\mathrm{HY})$ from Ref. 70.

${ }^{\mathrm{h}}$ Derived from $a \zeta_{\mathrm{e}}=-108 \mathrm{~cm}^{-1}$ (Ref. 42).

${ }^{\mathrm{i}}$ Estimated using Eq. (5).

${ }^{\mathrm{j}}$ From $a b$ initio value of $a\left(\mathrm{CH}_{3} \mathrm{Cl}^{+}\right)=-572.4 \mathrm{~cm}^{-1} \cdot{ }^{17}$

$\left(\mathrm{E}_{3 / 2}\right.$ and $\mathrm{E}_{1 / 2}$ ) of the vibronic ground state. These constants are summarized in the top row of the body of Table II.

The partitioning of $a \zeta_{\mathrm{e}} d_{j=1 / 2, v=0}$ into three distinct factors $a, \zeta_{\mathrm{e}}$ and $d_{j=1 / 2, v=0}$ is a challenging problem and cannot be done without assumptions and approximations. The constants $a$, which can be regarded in good approximation as arising from the halogen $(\mathrm{X}=\mathrm{F}, \mathrm{Cl}, \mathrm{Br}, \mathrm{I})$ or chalcogen atom $(\mathrm{Y}=\mathrm{O}, \mathrm{S})$, were chosen to be equal to the spin-orbit splittings $a\left(\mathrm{HX}^{+}\right)$and $a(\mathrm{HY})$ of the ${ }^{2} \Pi$ ground state of the corresponding $\mathrm{HX}^{+}$and $\mathrm{HY}$ molecules, respectively. The values of $a\left(\mathrm{HX}^{+}\right)$and $a(\mathrm{HY})$, summarized in the second row of the body of Table II, are almost exactly two thirds of the spinorbit coupling constants of $\mathrm{X}$ and $\mathrm{Y}^{-}$, as expected, and can therefore be considered atomic-like spin-orbit constants. For $\mathrm{CH}_{3} \mathrm{I}^{+}, a$ could be determined directly from the comparison of the spectra of $\mathrm{CH}_{3} \mathrm{I}^{+}$and $\mathrm{CD}_{3} \mathrm{I}^{+}$(see Ref. 15). We expect that the $a$ values summarized in Table II are accurate to within $\approx 10 \%$.

The ratio $a \zeta_{\mathrm{e}} d_{j=1 / 2, v=0} / a$ between the observed and the atomic-like spin-orbit constant is the overall reduction factor $\zeta_{\mathrm{e}} d_{j=1 / 2, v=0}$, listed in the third row of the body of Table II. The further separation of this overall reduction factor into $\zeta_{\mathrm{e}}$ and $d_{j=1 / 2, v=0}$ necessitates the combined analysis of the rotational and spin-vibronic structures of the photoelectron spectra.

In $\mathrm{CH}_{3} \mathrm{I}^{+}, d_{j=1 / 2, v=0}$ could be determined to be $\approx 1$ from the positions of rotational satellite bands of the origin bands of the photoelectron spectra of both $\mathrm{CH}_{3} \mathrm{I}^{+}$and $\mathrm{CD}_{3} \mathrm{I}^{+}$(see Ref. 15).

In the case of $\mathrm{CH}_{3} \mathrm{Cl}^{+}$, the spin-orbit coupling constant $a\left(\mathrm{CH}_{3} \mathrm{Cl}^{+}\right) \zeta_{\mathrm{e}}$ was determined to be $-572.4 \mathrm{~cm}^{-1}$ by ab initio quantum chemical methods, ${ }^{17}$ and the diatomic spin-orbit coupling constant $a\left(\mathrm{HF}^{+}\right)$is $-663.6 \mathrm{~cm}^{-1} .{ }^{49}$ From the measured spin-orbit splitting of $a \zeta_{\mathrm{e}} d_{j=1 / 2, v=0}=-217.5 \mathrm{~cm}^{-1}$ of the origin band of the photoelectron spectrum, ${ }^{16}$ and by taking the appropriate ratios, one obtains $\zeta_{\mathrm{e}}=0.86$ and $d_{j=1 / 2, v=0}$ $=0.4$.

In $\mathrm{CH}_{3} \mathrm{~F}^{+}$, which follows Hund's angular momentum coupling case (b), $d_{j, v}$ must be derived from the vibronic fine structure of the Jahn-Teller-active modes. By inserting the linear Jahn-Teller coupling strengths and the harmonic wave numbers of the Jahn-Teller-active modes $v_{4}, v_{5}$, and $v_{6}$ derived by Mahapatra and co-workers ${ }^{18,19}$ (see Tables III and IV) into the effective spin-vibronic Hamiltonian including only the linear Jahn-Teller coupling term, the product $a d_{j=1 / 2, v=0}$ was estimated to be about $16 \mathrm{~cm}^{-1}$. The atomiclike spin-orbit splitting is $242 \mathrm{~cm}^{-1},{ }^{45}$ so that $d_{j=1 / 2, v=0}$ $\approx 0.07$. The result $a \zeta_{\mathrm{e}} d_{j=1 / 2, v=0} \leq 2 \mathrm{~cm}^{-1}$ derived from the PFI-ZEKE photoelectron spectrum (see Sec. II A) thus implies that $\zeta_{\mathrm{e}} \leq 0.12$. $\zeta_{\mathrm{e}}$ is thus very small in the ground electronic state of $\mathrm{CH}_{3} \mathrm{~F}^{+}$and plays a major role in the reduction of the spin-orbit splitting.

In the case of $\mathrm{CH}_{3} \mathrm{O}$, the value $a \zeta_{\mathrm{e}}$ was reported to be $-108 \mathrm{~cm}^{-1}$ in Ref. 42. The values of $\zeta_{\mathrm{e}}$ and $d_{j, v}$ listed in Table II can be derived from the appropriate ratios.

$\mathrm{CH}_{3} \mathrm{~S}$ has a weak and essentially linear Jahn-Teller effect predominantly along $v_{6} .{ }^{2}$ Consequently, the value of $d_{j, v}$ can be estimated using the perturbation-theory relation between the Jahn-Teller strength $D_{i}$ in one Jahn-Teller-active e mode $v_{i}$ and $d_{j, v},{ }^{50}$

$$
d_{j, v}=\mp 1 \pm 4 D(v+1) \quad \text { for } \mathrm{j}=\ell_{\mathrm{v}} \mp \frac{1}{2} .
$$

By assuming a dominant Jahn-Teller effect along $v_{6}$, one obtains

$$
d_{j=1 / 2, v=0} \approx d_{j=1 / 2, v=0}^{6} \cong 1-4 D_{6}=0.82 .
$$

TABLE III. Main Jahn-Teller coupling parameters in the $\tilde{\mathrm{X}}^{+}{ }^{2} \mathrm{E}$ ground state of $\mathrm{CH}_{3} \mathrm{X}^{+}(\mathrm{X}=\mathrm{F}, \mathrm{Cl}, \mathrm{Br}, \mathrm{I})$ and $\mathrm{CH}_{3} \mathrm{Y}(\mathrm{Y}=\mathrm{O}, \mathrm{S})$.

\begin{tabular}{lcccc}
\hline \hline & $D_{4}$ & $D_{5}$ & $D_{6}$ & Ref. \\
\hline $\mathrm{CH}_{3} \mathrm{~F}^{+}$ & 0.07 & 0.71 & 0.31 & (Refs. 18 and 19) \\
$\mathrm{CH}_{3} \mathrm{Cl}^{+}$ & $\ldots$ & $0.3^{\mathrm{a}}$ & $0.4^{\mathrm{a}}$ & (Refs. 7 and 8) \\
& 0.007 & 0.073 & 0.203 & (Ref. 17) \\
$\mathrm{CH}_{3} \mathrm{Br}^{+}$ & $0.0012^{\mathrm{a}}$ & $\ldots$ & $0.0289^{\mathrm{a}}$ & (Refs. 7 and 8) \\
$\mathrm{CH}_{3} \mathrm{I}^{+}$ & $0.0005^{\mathrm{a}}$ & $\ldots$ & $0.0418^{\mathrm{a}}$ & (Refs. 7 and 8) \\
$\mathrm{CH}_{3} \mathrm{O}$ & 0.02 & 0.075 & 0.24 & (Ref. 2) \\
$\mathrm{CH}_{3} \mathrm{O}$ & 0.00016 & 0.01063 & 0.15716 & (Refs. 41 and 42) \\
$\mathrm{CH}_{3} \mathrm{~S}$ & $\ldots$ & $\ldots$ & 0.045 & (Ref. 2) \\
\hline
\end{tabular}

${ }^{\text {a There is an intrinsic difficulty in extracting } D_{i} \text { from experimental data in systems where }}$ the spin-orbit interaction is dominant. These values must probably be interpreted as upper bound. 
TABLE IV. Harmonic wave numbers (in $\mathrm{cm}^{-1}$ ) of the six vibrational modes of $\mathrm{CH}_{3} \mathrm{X}^{+}, \mathrm{CH}_{3} \mathrm{X}(\mathrm{X}=\mathrm{F}, \mathrm{Cl}, \mathrm{Br}, \mathrm{I})$, and $\mathrm{CH}_{3} \mathrm{Y}(\mathrm{Y}=\mathrm{O}, \mathrm{S})$ in $\mathrm{C}_{3 \mathrm{v}}$ symmetry.

\begin{tabular}{|c|c|c|c|c|c|c|}
\hline Mode & $\begin{array}{c}v_{1}\left(\mathrm{a}_{1}\right) \\
\mathrm{C}-\mathrm{H} \text { stretch }\end{array}$ & $\begin{array}{c}v_{2}\left(\mathrm{a}_{1}\right) \\
\text { Umbrella }\end{array}$ & $\begin{array}{c}\nu_{3}\left(\mathrm{a}_{1}\right) \\
\mathrm{C}-\mathrm{X}(\mathrm{Y}) \text { stretch }\end{array}$ & $\begin{array}{c}\nu_{4}(\mathrm{e}) \\
\mathrm{C}-\mathrm{H} \text { stretch }\end{array}$ & $\begin{array}{c}\nu_{5}(\mathrm{e}) \\
\mathrm{CH}_{3} \text { deformation }\end{array}$ & $\begin{array}{c}\nu_{6}(\mathrm{e}) \\
\mathrm{H}_{3} \mathrm{C}-\mathrm{X}(\mathrm{Y}) \text { bend }\end{array}$ \\
\hline $\mathrm{CH}_{3} \mathrm{~F}$ (Ref. 71) & 2964.5 & 1475.3 & 1048.2 & 2982.2 & 1471.1 & 1195.5 \\
\hline $\mathrm{CH}_{3} \mathrm{~F}^{+}$(Ref. 7) & $\ldots$ & $\ldots$ & 694 & $\ldots$ & 1315 & 879 \\
\hline $\mathrm{CH}_{3} \mathrm{~F}^{+}$(Ref. 28) & $\ldots$ & $\ldots$ & 1266 & $\ldots$ & 976 & 690 \\
\hline $\mathrm{CH}_{3} \mathrm{~F}^{+}$(Ref. 38) & 3228 & 1478 & 1321 & 2389.5 & 1062.5 & 916 \\
\hline $\mathrm{CH}_{3} \mathrm{~F}^{+}$(Ref. 18) & 2919 & 987 & 686 & 2978 & 947 & 1033 \\
\hline $\mathrm{CH}_{3} \mathrm{Cl}$ (Ref. 71) & 2966.2 & 1354.9 & 732.1 & 3041.8 & 1454.6 & 1015.0 \\
\hline $\mathrm{CH}_{3} \mathrm{Cl}^{+}$(Ref. 23) & $\ldots$ & 1514 & 871 & $\ldots$ & 1550 & $\ldots$ \\
\hline $\mathrm{CH}_{3} \mathrm{Cl}^{+}$(Ref. 7) & $\ldots$ & 1073 & 653 & $\ldots$ & 1545 & 871 \\
\hline $\mathrm{CH}_{3} \mathrm{Cl}^{+}$(Ref. 38) & $\ldots$ & 1239.5 & 638 & $\ldots$ & 1503.3 & $\ldots$ \\
\hline $\mathrm{CH}_{3} \mathrm{Cl}^{+}$(Ref. 29) & $\ldots$ & $\ldots$ & 613 & $\ldots$ & $\ldots$ & 839 \\
\hline $\mathrm{CH}_{3} \mathrm{Cl}^{+}$(Ref. 16) & $\ldots$ & 1554.2 & 647.5 & $\ldots$ & 1484 & 1059.5 \\
\hline $\mathrm{CH}_{3} \mathrm{Cl}^{+}$(Ref. 17) & 3009.4 & 1305.4 & 630.9 & 3148.2 & 1371.1 & 954.7 \\
\hline $\mathrm{CH}_{3} \mathrm{Br}$ (Ref. 71) & 2972 & 1305.1 & 611 & 3055.9 & 1445.3 & 952.0 \\
\hline $\mathrm{CH}_{3} \mathrm{Br}^{+}$(Ref. 7) & 2928 & 1290 & 468 & 3129 & $\ldots$ & 847 \\
\hline $\mathrm{CH}_{3} \mathrm{Br}^{+}$(Ref. 32) & 2899 & 1282 & 518 & 3077 & 1368 & 828 \\
\hline $\mathrm{CH}_{3} \mathrm{I}$ (Ref. 71) & 2969.8 & 1251.5 & 532.8 & 3060.3 & 1440.3 & 880.1 \\
\hline $\mathrm{CH}_{3} \mathrm{I}^{+}$(Ref. 7) & 2968 & 1254 & 492 & $\ldots$ & $\ldots$ & 919 \\
\hline $\mathrm{CH}_{3} \mathrm{I}^{+}$(Ref. 36) & 2938 & 1257 & 480 & 3043 & 1399 & 861 \\
\hline $\mathrm{CH}_{3} \mathrm{O}$ (Ref. 2) & $\ldots$ & 1359 & 1050.5 & 2835 & 1417 & 1065 \\
\hline $\mathrm{CH}_{3} \mathrm{O}$ (Ref. 41) & 3065 & 1470 & 1070 & 3153 & 1509 & 1116 \\
\hline $\mathrm{CH}_{3} \mathrm{~S}$ (Ref. 2) & 2776 & 1313 & 727 & $\ldots$ & $\ldots$ & 913 \\
\hline
\end{tabular}

\section{Linear Jahn-Teller coupling parameters}

The strength of the linear Jahn-Teller coupling along the active e modes is conveniently parametrized by the dimensionless Jahn-Teller parameter $D_{i}(i=4,5,6)$ for the three emodes. Values of $D_{i}$ for the three Jahn-Teller-active modes $v_{4}$ (asymmetric $\mathrm{C}-\mathrm{H}$ stretching mode), $v_{5}\left(\mathrm{CH}_{3}\right.$ deformation mode), and $v_{6}\left(\mathrm{H}_{3} \mathrm{C}-\mathrm{X}(\mathrm{Y})\right.$ bending mode), have been reported in the literature for most molecular systems of interest in the present article and are summarized in Table III.

The values obtained for $D_{i}$ depend on the approximations made in the treatment of the Jahn-Teller effect, e.g., whether quadratic and bilinear coupling terms were included or not, so that the comparison of values reported in different studies is not always straightforward. Nevertheless, Table III gives a qualitatively correct overview and enables one to recognize the following overall trends: (i) $D_{4}$ is always much smaller than $D_{5}$ and $D_{6}$. (ii) $D_{6}$ is largest in all molecules, except $\mathrm{CH}_{3} \mathrm{~F}^{+}$. (iii) Overall, the $D_{i}$ values decrease with increasing atomic number of $\mathrm{X}$ and $\mathrm{Y}$.

Because the values of $D_{i}$ in Table III need to be multiplied by the corresponding harmonic wave numbers to obtain the stabilization energies in wave number units, the harmonic wave numbers reported for all six modes (in $\mathrm{C}_{3 \mathrm{v}}$ symmetry) are given in Table IV. For comparison, Table IV also includes the harmonic wave numbers of the parent neutral molecules $\mathrm{CH}_{3} \mathrm{~F}, \mathrm{CH}_{3} \mathrm{Cl}, \mathrm{CH}_{3} \mathrm{Br}$, and $\mathrm{CH}_{3} \mathrm{I}$ in their ground electronic states.

As expected, the harmonic wave numbers of modes which do not involve the atom X or Y remain approximately the same for all molecules. The harmonic wave numbers of the modes directly involving $\mathrm{X}$ or $\mathrm{Y}$ (i.e., $v_{3}$ and $v_{6}$ ) decrease with increasing mass of $\mathrm{X}$ and $\mathrm{Y}$, as expected. $\mathrm{CH}_{3} \mathrm{~F}^{+}$seems, however, to represent an exception in that the wave num- ber of the antisymmetric $\mathrm{C}-\mathrm{H}$ stretching mode is reduced ( $\sim 2400 \mathrm{~cm}^{-1}$ instead of $\sim 3000 \mathrm{~cm}^{-1}$ in the other molecules) and the wave number of the $\mathrm{C}-\mathrm{F}$ stretching mode increases instead of decreasing, as in the heavier methyl-halide cations.

\section{A SIMPLE EXCITONIC MODEL DESCRIBING THE $\tilde{X}^{+2}$ E STATE}

\section{A. The $\tilde{\mathbf{X}}^{+}{ }^{2} \mathrm{E}$ state of $\mathrm{CH}_{3} \mathrm{X}^{+}$}

The data presented in Section II appear to confirm the overall expectation that the strength of the spin-orbit and Jahn-Teller interactions follow opposite trends, molecules with the largest spin-orbit interactions having the weakest Jahn-Teller coupling and vice versa. The data, however, also reveal that $\mathrm{CH}_{3} \mathrm{~F}^{+}$represents an exception to this behavior in that the strong reduction of the spin-orbit interaction cannot solely originate from the Jahn-Teller interaction. Table II indicates that the anomalous reduction of the spin-orbit splitting in $\mathrm{CH}_{3} \mathrm{~F}^{+}$is an electronic effect and must be interpreted as arising from a different electronic structure. A similar conclusion has been drawn in earlier studies, in particular, by Karlsson and co-workers. ${ }^{7,8}$ The fact that $\zeta_{\mathrm{e}}$ is close to 1 only in $\mathrm{CH}_{3} \mathrm{Br}^{+}$and $\mathrm{CH}_{3} \mathrm{I}^{+}$further indicates that the electronic effect that alters the behavior observed in the ground state of $\mathrm{CH}_{3} \mathrm{~F}^{+}$also affects $\mathrm{CH}_{3} \mathrm{Cl}^{+}, \mathrm{CH}_{3} \mathrm{O}$, and $\mathrm{CH}_{3} \mathrm{~S}$, though in a less pronounced manner.

The simplest way by which the spin-orbit interaction in molecules of the type $\mathrm{CH}_{3} \mathrm{X}^{+}$and $\mathrm{CH}_{3} \mathrm{Y}$ can be quenched electronically is a charge transfer to the methyl side of the molecules. This section presents a simple two-state excitonic model we developed to model this charge transfer qualitatively. 
In solid-state physics, excitons represent bound states of electron-hole pairs, the binding being induced by the Coulomb interaction. ${ }^{51}$ In molecular physics, excitons refer to localized electronic excitations in systems that can be decomposed into two (or more) subsystems, examples being bipheny ${ }^{52}$ or molecular dimers such as pyridone dimers. ${ }^{53}$ One subsystem, the electron acceptor, acts as an electron hole, and exerts an attractive force on an electron-rich subsystem which acts as an electron donor. The overall system is described as two subsystems A and B coupled by an interaction $V_{\text {exc. }}$.

To model the ${ }^{2} \mathrm{E}$ states of the methyl-halide cations, we consider these molecules as consisting of a halogen-atom subsystem and a pyramidal-methyl-group subsystem. The ${ }^{2} \mathrm{E}$ states are produced by removing an electron out of the doubly degenerate orbital of either of these two systems. In the case of the halogen atom, the relevant orbitals are the valence $\mathrm{p}_{x}$ and $\mathrm{p}_{y}$ orbitals that are oriented perpendicularly to the $\mathrm{C}-\mathrm{X}$ bond. In the case of the pyramidal methyl, the orbitals are linear combinations of the $\mathrm{C}-\mathrm{H}$ orbitals of e symmetry. The excitonic system therefore involves $\pi$-type orbitals, i.e., orbitals having one nodal plane containing the $\mathrm{C}-\mathrm{X}$ axis, and does not affect the $\sigma$-type $\mathrm{C}-\mathrm{X}$ bond directly. The excitonic system is created upon ionization of the neutral molecule. Ionization from the $\mathrm{p}_{x, y}$ orbitals of X leads to an electron hole $\varphi_{\mathrm{X}}$ on the halogen atom and ionization from the "e" valence orbital of the pyramidal methyl leads to an electron hole $\varphi_{\mathrm{CH}_{3}}$ spread over the three $\mathrm{C}-\mathrm{H}$ bonding orbitals. The energies of the cationic states are obtained by considering the excitonic coupling between the two moieties.

In the model, the $\tilde{\mathrm{X}}{ }^{1} \mathrm{~A}_{1}$ ground electronic state of the neutral molecule $\mathrm{CH}_{3} \mathrm{X}$ defines the common energy reference of the excitonic system. The energies of the noninteracting subsystems are taken to be the $\left(\mathrm{p}_{\mathrm{x}, \mathrm{y}}\right)^{-1}$ ionization energy of the halogen atom, which we take as the center of gravity of the ${ }^{2} \mathrm{P}_{3 / 2}$ and ${ }^{2} \mathrm{P}_{1 / 2}$ thresholds, and the vertical ionization energy of methane, rather than methyl. The reason for this choice is that methyl is planar in its electronic ground state and its first ionization energy corresponds to the removal of the unpaired electron from the nondegenerate $2 \mathrm{p}_{z}$ lone pair of the carbon atom. ${ }^{54}$ The outer-valence-shell photoionization of methane leads to the formation of the $\tilde{\mathrm{X}}^{2} \mathrm{~F}_{2}$ ground state of $\mathrm{CH}_{4}^{+}$which is much more similar to the ${ }^{2} \mathrm{E}$ state resulting from ionization of the e orbital of a fictive pyramidal $\mathrm{CH}_{3}$ group.

The excitonic system is depicted schematically in Fig. 3. The interaction term $V_{\text {exc }}$ couples the two electron-hole pair states. Mathematically, the exciton system with interaction $V_{\text {exc }}$ can be described by a $2 \times 2$ matrix $\mathbf{H}_{\text {exc }}$,

$$
\mathbf{H}_{\mathrm{exc}}=\left(\begin{array}{cc}
E_{\mathrm{I}}\left(\mathrm{CH}_{4}\right) & V_{\mathrm{exc}} \\
V_{\mathrm{exc}} & E_{\mathrm{I}}(\mathrm{X})
\end{array}\right) .
$$

The eigenvalues

$$
\begin{aligned}
E_{ \pm}= & \frac{E_{\mathrm{I}}\left(\mathrm{CH}_{4}\right)+E_{\mathrm{I}}(\mathrm{X})}{2} \\
& \pm \frac{1}{2} \sqrt{E_{\mathrm{I}}\left(\mathrm{CH}_{4}\right)^{2}+E_{\mathrm{I}}(\mathrm{X})^{2}-2 E_{\mathrm{I}}\left(\mathrm{CH}_{4}\right) E_{\mathrm{I}}(\mathrm{X})+4 V_{\mathrm{exc}}^{2}}
\end{aligned}
$$

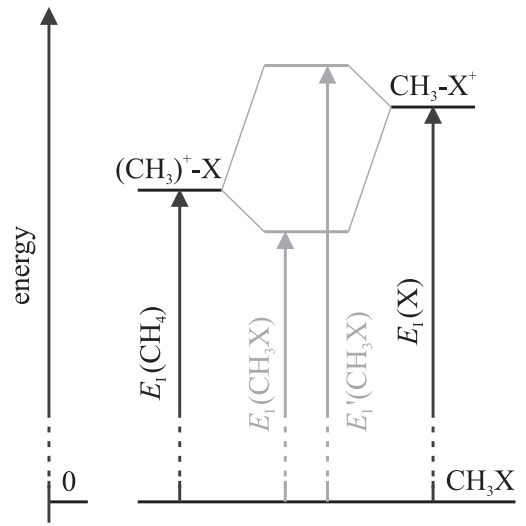

FIG. 3. Schematic diagram of the two-state excitonic model, where either methane (left-hand side) or the halogen atom (right-hand side) is ionized and becomes the electron donor. The gray horizontal lines mark the eigenvalues of the excitonic coupling matrix $\mathbf{H}_{\text {exc }}$ obtained using Eq. (6) which correspond to the lowest and a higher lying ${ }^{2} \mathrm{E}$ electronic state in the methyl-halide cation. The ionization energies $E_{\mathrm{I}}$ are indicated by vertical arrows.

of $\mathbf{H}_{\mathrm{exc}}$ give the predicted positions of the $\tilde{\mathrm{X}}^{+2} \mathrm{E}$ ground state $\left(\mathrm{E}_{-}\right)$and the $\tilde{\mathrm{B}}^{+2} \mathrm{E}$ excited state $\left(\mathrm{E}_{+}\right)$of $\mathrm{CH}_{3} \mathrm{X}^{+}$. The corresponding eigenstates are

$$
\begin{gathered}
\varphi_{-}=-a_{\mathrm{CH}_{3}} \varphi_{\mathrm{CH}_{3}}+a_{\mathrm{X}} \varphi_{\mathrm{X}} \quad \text { and } \\
\varphi_{+}=a_{\mathrm{X}} \varphi_{\mathrm{CH}_{3}}+a_{\mathrm{CH}_{3}} \varphi_{\mathrm{X}},
\end{gathered}
$$

respectively, with $a_{\mathrm{CH}_{3}}^{2}+a_{\mathrm{X}}^{2}=1$.

Apart from the interaction term $V_{\text {exc }}$, the model does not involve any adjustable parameters, because the ionization energies of the halogen atoms ${ }^{55-57}$ and the vertical ionization energy of $\mathrm{CH}_{4}$, which corresponds to the sum of the adiabatic ionization energy of $\mathrm{CH}_{4}$ (Ref. 58) and the Jahn-Teller stabilization energy of $\mathrm{CH}_{4}^{+}\left(12100 \mathrm{~cm}^{-1}\right.$ (Ref. 59)), are known.

The values for these quantities used in our calculations are summarized in Table V. We further assume that the interaction term $V_{\mathrm{exc}}$ is the same for all molecules. This choice has the advantage of reducing the number of adjustable parameters to a single one and can be justified by the similarity of the molecular systems under investigation and by the fact that our model aims at a qualitative understanding only.

To determine the optimal value of $V_{\text {exc }}$, we compared the ionization energies corresponding to the $\tilde{X}^{+}{ }^{2} \mathrm{E}$ $\left(E_{\mathrm{I}}\left(\mathrm{CH}_{3} \mathrm{X}\right)\right)$ ground and the $\tilde{\mathrm{B}}^{+}{ }^{2} \mathrm{E}\left(E_{\mathrm{I}}^{\prime}\left(\mathrm{CH}_{3} \mathrm{X}\right)\right)$ excited state with values determined from photoelectron spectra, which are summarized on the left-hand side of Table VI. The comparison is illustrated in Fig. 4, which displays the differences $\Delta E_{\mathrm{I}}\left(\mathrm{CH}_{3} \mathrm{X}\right)=E_{\mathrm{I}}^{\text {calc }}\left(\mathrm{CH}_{3} \mathrm{X}\right)-E_{\mathrm{I}}^{\exp }\left(\mathrm{CH}_{3} \mathrm{X}\right)$ and $\Delta E_{\mathrm{I}}^{\prime}\left(\mathrm{CH}_{3} \mathrm{X}\right)=E_{\mathrm{I}}^{\text {calc }}\left(\mathrm{CH}_{3} \mathrm{X}\right)-E_{\mathrm{I}}^{\text {exp }}\left(\mathrm{CH}_{3} \mathrm{X}\right)$ as a function of the interaction parameter $V_{\mathrm{exc}}$. For values of $V_{\mathrm{exc}}$ below

TABLE V. Atomic ionization energies ${ }^{55-57}$ (in $\mathrm{cm}^{-1}$ ), determined as the center-of-gravity energies of the neutral and ionic states, and vertical ionization energy of methane ${ }^{58,59}$ (in $\mathrm{cm}^{-1}$ ).

\begin{tabular}{lcccccc}
\hline \hline$E_{\mathrm{I}}(\mathrm{F})$ & $E_{\mathrm{I}}(\mathrm{Cl})$ & $E_{\mathrm{I}}(\mathrm{Br})$ & $E_{\mathrm{I}}(\mathrm{I})$ & $E_{\mathrm{I}}(\mathrm{O})$ & $E_{\mathrm{I}}(\mathrm{S})$ & $E_{\mathrm{I}}\left(\mathrm{CH}_{4}\right)$ \\
\hline 140587 & 105040 & 95795 & 84886 & 109759 & 83363 & 113900 \\
\hline
\end{tabular}




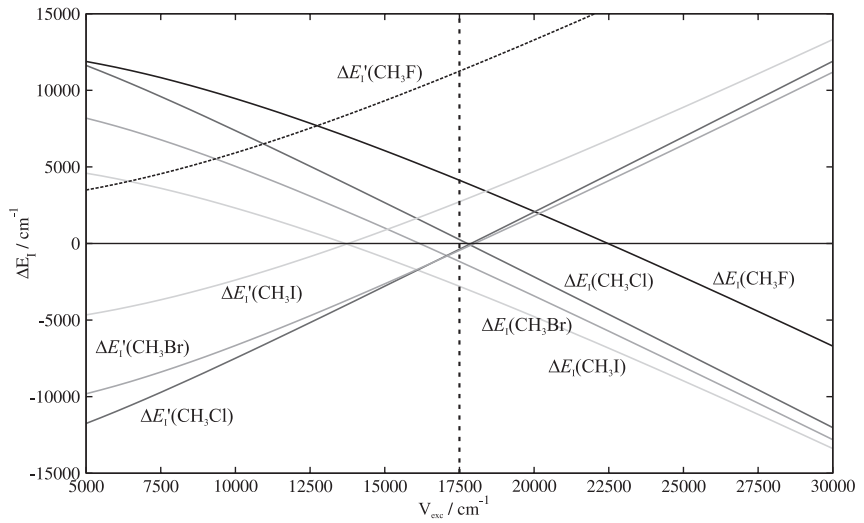

FIG. 4. Energy differences between calculated and experimental ionization energies $\left(\Delta E_{\mathrm{I}}=E_{\mathrm{I}}^{\text {calc }}-E_{\mathrm{I}}^{\mathrm{exp}}\right)$ of the methyl-halide cations as a function of the interaction potential $V_{\mathrm{exc}}$. The $\Delta E_{\mathrm{I}}$ of the lower $\left(E_{\mathrm{I}}\right)$ and upper $\left(E_{\mathrm{I}}^{\prime}\right)^{2} \mathrm{E}$ electronic states are decreasing and increasing in energy for an increasing interaction potential $V_{\text {exc }}$, respectively. The states from $\mathrm{CH}_{3} \mathrm{~F}^{+}$ to $\mathrm{CH}_{3} \mathrm{I}^{+}$are shown as black to gray lines of decreasing blackness, and $\Delta E_{\mathrm{I}}^{\prime}\left(\mathrm{CH}_{3} \mathrm{~F}\right)$ is shown as dotted line because of the large uncertainty in the experimental determination of this ionization energy. The dashed vertical line $\left(V_{\mathrm{exc}}=17500 \mathrm{~cm}^{-1}\right)$ marks the strength of the interaction potential where $\Delta E_{\mathrm{I}}$ and $\Delta E_{\mathrm{I}}^{\prime}$ are minimized.

$12500 \mathrm{~cm}^{-1}$ (left-hand side of Fig. 4), the calculation overestimates the values of $E_{\mathrm{I}}$ and underestimates those of $E_{\mathrm{I}}^{\prime}$. This situation reverses for $V_{\text {exc }}$ values beyond $22500 \mathrm{~cm}^{-1}$ (see right-hand side of Fig. 4).

The value of $V_{\text {exc }}$ which minimizes the deviations between calculated and experimental values of the ionization energies $\left(17500 \mathrm{~cm}^{-1}\right)$ is indicated by a dashed vertical line in Fig. 4. At this value, the agreement between predicted and experimental ionization energies is almost perfect for $\mathrm{CH}_{3} \mathrm{Cl}$ and $\mathrm{CH}_{3} \mathrm{Br}$. To minimize $\Delta E_{\mathrm{I}}\left(\mathrm{CH}_{3} \mathrm{I}\right)$ and $\Delta E_{\mathrm{I}}^{\prime}\left(\mathrm{CH}_{3} \mathrm{I}\right)$, a value of $V_{\text {exc }}$ of $\approx 13500 \mathrm{~cm}^{-1}$ would have been better than 17500 $\mathrm{cm}^{-1}$, whereas a value of $V_{\text {exc }}$ of $\approx 22000 \mathrm{~cm}^{-1}$ would be needed to correctly predict $E_{\mathrm{I}}\left(\mathrm{CH}_{3} \mathrm{~F}\right)$. The experimental value of $E_{\mathrm{I}}^{\prime}\left(\mathrm{CH}_{3} \mathrm{~F}\right)$ cannot be reproduced by the model for any value of $V_{\text {exc }}$. However, the experimental value of $E_{\mathrm{I}}^{\prime}\left(\mathrm{CH}_{3} \mathrm{~F}\right)$ is not

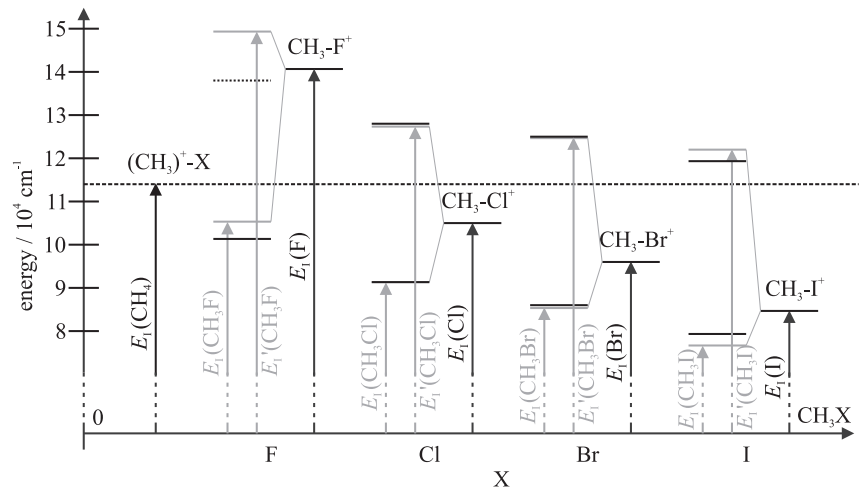

FIG. 5. Schematic energy diagram presenting the ionization energies $E_{\mathrm{I}}$ of methane and the halogen atoms (black vertical arrows), which are coupled by the excitonic matrix $\mathbf{H}_{\text {exc }}$ (Eq. (6)) by an interaction potential $V_{\text {exc }}=17500$ $\mathrm{cm}^{-1}$. The resulting eigenvalues, which represent the lowest and a higher lying ${ }^{2} \mathrm{E}$ state in the methyl-halide cations, are marked by gray horizontal lines, and the corresponding experimental ionization energies ${ }^{66}$ are marked by black horizontal lines. The energy of the upper ${ }^{2} \mathrm{E}$ electronic state of $\mathrm{CH}_{3} \mathrm{~F}^{+}$derived from photoelectron spectra ${ }^{7,66}$ is marked by a dotted line, because there is a large experimental uncertainty to its energy, see text for details.

well established, because the $\mathrm{CH}_{3} \mathrm{~F}^{+} \tilde{\mathrm{B}}^{+2} \mathrm{E} \leftarrow \mathrm{CH}_{3} \mathrm{~F} \tilde{\mathrm{X}}{ }^{1} \mathrm{~A}_{1}$ band of the photoelectron spectrum is very broad and overlaps with the $\mathrm{CH}_{3} \mathrm{~F}^{+} \tilde{\mathrm{A}}^{+2} \mathrm{E} \leftarrow \mathrm{CH}_{3} \mathrm{~F} \tilde{\mathrm{X}}^{1} \mathrm{~A}_{1}$ band (see, e.g., Ref. 7). The results depicted in Fig. 4 suggest that $V_{\mathrm{exc}}$ actually decreases from $\mathrm{CH}_{3} \mathrm{~F}^{+}$to $\mathrm{CH}_{3} \mathrm{I}^{+}$, which highlights one of the limitations of our assumption of a constant value $\left(17500 \mathrm{~cm}^{-1}\right)$ of $V_{\text {exc }}$.

The predictions of our simple two-state exciton model for $V_{\mathrm{exc}}=17500 \mathrm{~cm}^{-1}$ are compared to experimental results in Fig. 5, where the calculated values of $E_{\mathrm{I}}$ and $E_{\mathrm{I}}^{\prime}$ are indicated as gray horizontal lines and the experimental values as black horizontal lines. In view of the simple nature and the crude assumptions of the model, the agreement between calculated and experimental values of the ionization energies corresponding to the lowest two cationic states of ${ }^{2} \mathrm{E}$ symmetry must be regarded as surprisingly good, most deviations being significantly less than $0.5 \mathrm{eV}$.

TABLE VI. Ionization energies $E_{\mathrm{I}}\left(\mathrm{CH}_{3} \mathrm{X}\right)$ and $E_{\mathrm{I}}^{\prime}\left(\mathrm{CH}_{3} \mathrm{X}\right)\left(E_{\mathrm{I}}\left(\mathrm{CH}_{3} \mathrm{Y}\right)\right.$ and $\left.E_{\mathrm{I}}^{\prime}\left(\mathrm{CH}_{3} \mathrm{Y}\right)\right)$ to the lowest and a higher lying electronic state of $\mathrm{CH}_{3} \mathrm{X}^{+}\left(\mathrm{CH}_{3} \mathrm{Y}^{+}\right)$, determined from photoelectron spectroscopic studies ("Experiment") and with the exciton-type model of Eq. (6) using an interaction potential $V_{\text {exc }}=17500$ $\mathrm{cm}^{-1}$ ("Model"). In the last two columns, the differences between the calculated and experimentally determined ionization energies $\left(\Delta E_{\mathrm{I}}\right.$ and $\left.\Delta E_{\mathrm{I}}^{\prime}\right)$ are presented.

\begin{tabular}{|c|c|c|c|c|c|c|}
\hline \multirow[b]{2}{*}{$\mathrm{X}$} & \multicolumn{2}{|c|}{ Experiment } & \multicolumn{2}{|c|}{ Model } & \multirow[b]{2}{*}{$\Delta E_{\mathrm{I}}\left(\mathrm{CH}_{3} \mathrm{X}\right)$} & \multirow[b]{2}{*}{$\Delta E_{\mathrm{I}}^{\prime}\left(\mathrm{CH}_{3} \mathrm{X}\right)$} \\
\hline & $E_{\mathrm{I}}\left(\mathrm{CH}_{3} \mathrm{X}\right)$ & $E_{\mathrm{I}}^{\prime}\left(\mathrm{CH}_{3} \mathrm{X}\right)^{\mathrm{a}}$ & $E_{\mathrm{I}}\left(\mathrm{CH}_{3} \mathrm{X}\right)$ & $E_{\mathrm{I}}^{\prime}\left(\mathrm{CH}_{3} \mathrm{X}\right)$ & & \\
\hline $\mathrm{F}$ & $101109.0^{\mathrm{b}}$ & $(138000)$ & 105237 & 149250 & 4128 & (11250) \\
\hline $\mathrm{Cl}$ & $91165.8^{c}$ & 127900 & 91418 & 127522 & 252 & -378 \\
\hline $\mathrm{Br}$ & $86321^{\mathrm{d}}$ & 125000 & 85145 & 124550 & -1176 & -450 \\
\hline I & $79459^{d}$ & 119400 & 76662 & 122124 & -2797 & 2724 \\
\hline $\mathrm{Y}$ & $E_{\mathrm{I}}\left(\mathrm{CH}_{3} \mathrm{Y}\right)$ & $E_{\mathrm{I}}^{\prime}\left(\mathrm{CH}_{3} \mathrm{Y}\right)$ & $E_{\mathrm{I}}\left(\mathrm{CH}_{3} \mathrm{Y}\right)$ & $E_{\mathrm{I}}^{\prime}\left(\mathrm{CH}_{3} \mathrm{Y}\right)$ & $\Delta E_{\mathrm{I}}\left(\mathrm{CH}_{3} \mathrm{Y}\right)$ & $\Delta E_{\mathrm{I}}^{\prime}\left(\mathrm{CH}_{3} \mathrm{Y}\right)$ \\
\hline $\mathrm{O}$ & $86480^{\mathrm{e}}$ & $\ldots$ & 94207 & 129452 & 7727 & $\ldots$ \\
\hline$S$ & $74575^{\mathrm{f}}$ & $\ldots$ & 75407 & 121856 & 832 & $\ldots$ \\
\hline
\end{tabular}

a Reference 66

${ }^{\mathrm{b}}$ Reference 20.

${ }^{\mathrm{c}}$ Reference 16

${ }^{\mathrm{d}}$ Reference 32

${ }^{\mathrm{e}}$ Reference 67.

${ }^{\mathrm{f}}$ Reference 68. 
TABLE VII. Values of $a_{\mathrm{X}(\mathrm{Y})}, a_{\mathrm{X}(\mathrm{Y})}^{2}$, and $a_{\mathrm{CH}_{3}}$, determined with $V_{\mathrm{exc}}$ $=17500 \mathrm{~cm}^{-1}$, and the comparison to $\zeta_{\mathrm{e}}$ of the $\tilde{\mathrm{X}}^{+}{ }^{2} \mathrm{E}$ ground states of $\mathrm{CH}_{3} \mathrm{X}^{+}$and $\mathrm{CH}_{3} \mathrm{Y}$.

\begin{tabular}{lcccccc}
\hline \hline & $\mathrm{CH}_{3} \mathrm{~F}^{+}$ & $\mathrm{CH}_{3} \mathrm{Cl}^{+}$ & $\mathrm{CH}_{3} \mathrm{Br}^{+}$ & $\mathrm{CH}_{3} \mathrm{I}^{+}$ & $\mathrm{CH}_{3} \mathrm{O}$ & $\mathrm{CH}_{3} \mathrm{~S}$ \\
\hline$a_{\mathrm{X}(\mathrm{Y})}$ & -0.444 & 0.789 & 0.854 & 0.905 & 0.747 & 0.910 \\
$a_{\mathrm{CH}_{3}}$ & 0.896 & -0.614 & -0.520 & -0.425 & -0.664 & -0.414 \\
$a_{\mathrm{X}(\mathrm{Y})}^{2}$ & 0.20 & 0.62 & 0.73 & 0.82 & 0.56 & 0.83 \\
$\zeta_{\mathrm{e}}$ & $<0.12$ & 0.86 & $\cdots$ & {$[0.97,1.0]$} & 0.78 & 0.82 \\
\hline \hline
\end{tabular}

The exciton model enables one to quantify the degree of charge transfer from the halogen side to the pyramidal-methyl side (and vice versa) of the cation and, therefore, to derive values of the purely electronic reduction factor $\zeta_{\mathrm{e}}$ of the spinorbit splitting, which is equal to $a_{\mathrm{X}}^{2}$. The calculated values of $a_{\mathrm{X}}^{2}$ are listed in Table VII, where they are compared with the values of $\zeta_{\mathrm{e}}$ determined for the $\tilde{\mathrm{X}}^{+2} \mathrm{E}$ ground state of $\mathrm{CH}_{3} \mathrm{X}^{+}$ from the analysis of the spin-orbit splittings (see bottom row of Table II).

The data presented in Table VII lead to the following conclusions: (1) The $\tilde{\mathrm{X}}^{+}{ }^{2} \mathrm{E}$ ground state of $\mathrm{CH}_{3} \mathrm{~F}^{+}$must be regarded as having an electron hole of significant pyramidalmethylic character, while all other $\mathrm{CH}_{3} \mathrm{X}^{+}$cations have an electron hole of dominant halogenic character. (2) The trend in $\zeta_{\mathrm{e}}$ observed experimentally qualitatively follows the trend in the $a_{\mathrm{X}}^{2}$ values obtained with the simple excitonic model, which supports the intuition that $\zeta_{\mathrm{e}}$ must be interpreted as a transfer of the electron spin density from the halogen atom to the pyramidal-methyl side of the molecule in the $\tilde{X}^{+{ }^{2}} \mathrm{E}$ state. (3) Removing an electron from an (e) orbital of the pyramidal-methyl side of the molecule is expected to weaken the $\mathrm{C}-\mathrm{H}$ bonds and, therefore, to lead to (i) a reduction of the harmonic frequency of $\mathrm{C}-\mathrm{H}$ stretching modes, (ii) a dominant Jahn-Teller activity of the $\mathrm{CH}_{3}$ deformation mode $v_{5}$, and (iii) a strengthening of the $\mathrm{C}-\mathrm{F}$ bond by the addition of a charge-induced dipole contribution, which in turn results in Franck-Condon activity in this mode and in an increase of the $\mathrm{C}-\mathrm{F}$ stretching frequency. These expectations are confirmed by the experimental data summarized in Sec. II (see Tables II- IV). (4) Removing an electron from a nonbonding (e) orbital of the halogen (chalcogen) side of the molecule is neither expected to significantly affect the $\mathrm{C}-\mathrm{H}$ stretching and deformation modes nor the $\mathrm{C}-\mathrm{X}$ stretching modes (the methyl group is not easily polarizable). Its main effect should be to induce Jahn-Teller activity in the $\mathrm{H}_{3} \mathrm{C}-\mathrm{X}$ bending (e) mode $v_{6}$. These expectations are overall also confirmed by the data summarized in Sec. II. One should note, however, that this e orbital was found to be of slight antibonding character. ${ }^{7,18}$

\section{B. Extension of the exciton model to $\mathrm{CH}_{3} \mathrm{Y}(\mathrm{Y}=\mathrm{O}, \mathrm{S})$}

The ionization energies of $\mathrm{CH}_{4}$ and $\mathrm{Y}(=\mathrm{O}, \mathrm{S})$ can also be used to derive an exciton-type two-state model for $\mathrm{CH}_{3} \mathrm{Y}$, as illustrated in Fig. 6. However, rather than representing the ionization energies to the two ${ }^{2} \mathrm{E}$ states of the $\mathrm{CH}_{3} \mathrm{X}^{+}$radical cation from the ground state of $\mathrm{CH}_{3} \mathrm{X}$, the diagram now repre-

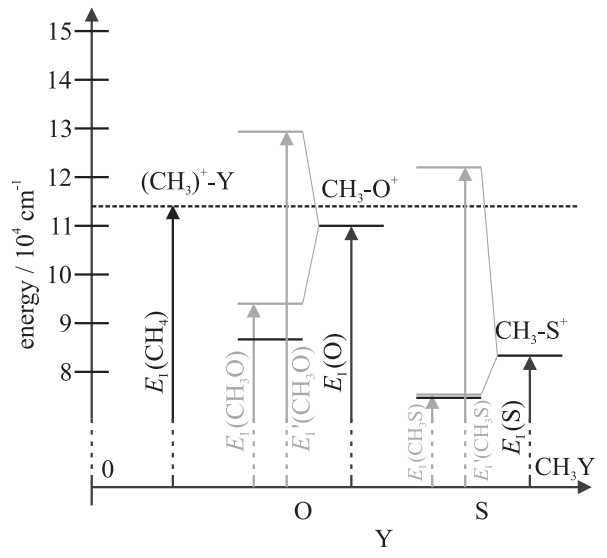

FIG. 6. Schematic energy diagram presenting the ionization energies $E_{\mathrm{I}}$ of methane and of atomic oxygen and sulphur (black vertical arrows), which are coupled in the excitonic matrix $\mathbf{H}_{\text {exc }}$ (Eq. (6)) by an interaction potential $V_{\text {exc }}=17500 \mathrm{~cm}^{-1}$. The resulting eigenvalues are marked by gray horizontal lines, and the corresponding experimental ionization energies ${ }^{67,68}$ are marked by black horizontal lines.

sents the Koopman's ionization energies from two (e) orbitals of the neutral radical, the higher being partially occupied.

The model disregards the fact that the ionic states have a fine structure and is even more approximate than in the case of the $\mathrm{CH}_{3} \mathrm{X}^{+}$molecules. The ionization energies predicted by the model are summarized in the bottom two rows of Table VI, and the coefficients $a_{\mathrm{CH}_{3}}$ and $a_{\mathrm{Y}}$ are listed in Table VII. The electronic reduction factor $\zeta_{\mathrm{e}}$ is predicted to be 0.56 in the ground state of $\mathrm{CH}_{3} \mathrm{O}$ and 0.83 in the ground state of $\mathrm{CH}_{3} \mathrm{~S}$, which is in good agreement with the value of 0.82 estimated from experimental results (Table VII).

Alternatively, $\mathrm{CH}_{3} \mathrm{O}$ and $\mathrm{CH}_{3} \mathrm{~S}$ can be described using an exciton-type model which is analogous to that used for the $\mathrm{CH}_{3} \mathrm{X}^{+}$cations and consists of using the ground state of $\mathrm{CH}_{3} \mathrm{Y}^{-}$as reference and the electron affinities $(E A)$ of $\mathrm{CH}_{4}, \mathrm{O}$, and $\mathrm{S}$, to determine the energies of the two excitonic zero-order states with the electron hole located on the pyramidal methyl and the chalcogenic atom, respectively. The main deficiency of this approach is that $\mathrm{CH}_{4}^{-}$is unstable and the electron affinity of $\mathrm{CH}_{4}$ not precisely known, see, e.g., Refs. 60-62. In the calculations presented here, the value $E A\left(\mathrm{CH}_{4}\right)=-1.906 \mathrm{eV}$ derived ab initio $^{62}$ was considered to be the most reliable estimate and therefore chosen. The excitonic matrix is set up analogously to that of Eq. (6), but using the electron affinities (summarized in Table VIII) instead of the ionization energies

$$
\mathbf{H}_{\mathrm{exc}}^{\prime}=\left(\begin{array}{cc}
E A\left(\mathrm{CH}_{4}\right) & V_{\mathrm{exc}} \\
V_{\mathrm{exc}} & E A(\mathrm{Y})
\end{array}\right) .
$$

TABLE VIII. Electron affinities for the chalcogen atoms, ${ }^{69}$ methane, ${ }^{62}$ $\mathrm{CH}_{3} \mathrm{O},{ }^{63}$ and $\mathrm{CH}_{3} \mathrm{~S}$ (Ref. 64) (in $\mathrm{cm}^{-1}$ ).

\begin{tabular}{ccccc}
\hline \hline$E A(\mathrm{O})$ & $E A(\mathrm{~S})$ & $E A\left(\mathrm{CH}_{4}\right)$ & $E A\left(\mathrm{CH}_{3} \mathrm{O}\right)$ & $E A\left(\mathrm{CH}_{3} \mathrm{~S}\right)$ \\
\hline 11785 & 16753 & -15373 & 12663 & 15058 \\
\hline \hline
\end{tabular}


TABLE IX. Values of $E A, a_{\mathrm{Y}}^{\prime}, a_{\mathrm{Y}}^{\prime 2}$, and $a_{\mathrm{CH}_{3}}^{\prime}$, determined with $V_{\mathrm{exc}}$ $=17500 \mathrm{~cm}^{-1}$, and the comparison to $\zeta_{\mathrm{e}}$ of the $\tilde{\mathrm{X}}^{2} \mathrm{E}$ ground state of $\mathrm{CH}_{3} \mathrm{Y}$.

\begin{tabular}{lcc}
\hline \hline$E A$ & $\begin{array}{c}\mathrm{CH}_{3} \mathrm{O} \\
20356 \mathrm{~cm}^{-1}\end{array}$ & $\begin{array}{c}\mathrm{CH}_{3} \mathrm{~S} \\
24444 \mathrm{~cm}^{-1}\end{array}$ \\
\hline$a^{\prime}{ }_{\mathrm{Y}}$ & 0.898 & 0.915 \\
$a^{\prime} \mathrm{CH}_{3}$ & 0.440 & 0.402 \\
$a_{\mathrm{Y}}^{\prime 2}$ & 0.81 & 0.84 \\
$\zeta_{\mathrm{e}}$ & 0.78 & 0.82 \\
\hline \hline
\end{tabular}

Consequently, the corresponding eigenstates are

$$
\begin{gathered}
\varphi_{-}^{\prime}=-a_{\mathrm{CH}_{3}}^{\prime} \varphi_{\mathrm{CH}_{3}}+a_{\mathrm{Y}}^{\prime} \varphi_{\mathrm{Y}} \text { and } \\
\varphi_{+}^{\prime}=a_{\mathrm{Y}}^{\prime} \varphi_{\mathrm{CH}_{3}}+a_{\mathrm{CH}_{3}}^{\prime} \varphi_{\mathrm{Y}},
\end{gathered}
$$

respectively, with $a_{\mathrm{CH}_{3}}^{\prime 2}+a_{\mathrm{Y}}^{\prime 2}=1$.

The results of the calculations using the excitonic model for $\mathrm{CH}_{3} \mathrm{O}$ and $\mathrm{CH}_{3} \mathrm{~S}$ with the electron affinities are summarized in Table IX and presented graphically in Figure 7 as gray horizontal bars, which allows the comparison to the experimentally determined values for the electron affinities (black horizontal bars). ${ }^{63,64}$ The somewhat larger discrepancy between the calculated and the experimentally determined values for the electron affinities can be explained by the large uncertainty in $E A\left(\mathrm{CH}_{4}\right)$. Nevertheless, this excitonic model reproduces the magnitude of $\zeta_{\mathrm{e}}$ observed experimentally in a semi-quantitative manner for both $\mathrm{CH}_{3} \mathrm{O}$ and $\mathrm{CH}_{3} \mathrm{~S}$, as can be seen from the bottom rows of Table IX. Our results also suggest that the theoretical value of $-1.906 \mathrm{eV}$ (Ref. 62) for the electron affinity of methane should be preferred to other values.

The extension of the simple excitonic model to the molecules $\mathrm{CH}_{3} \mathrm{O}$ and $\mathrm{CH}_{3} \mathrm{~S}$ therefore explains why the reduction of the spin-orbit splitting is much more pronounced in $\mathrm{CH}_{3} \mathrm{~F}^{+}$than it is in the isoelectronic neutral molecule $\mathrm{CH}_{3} \mathrm{O}$.

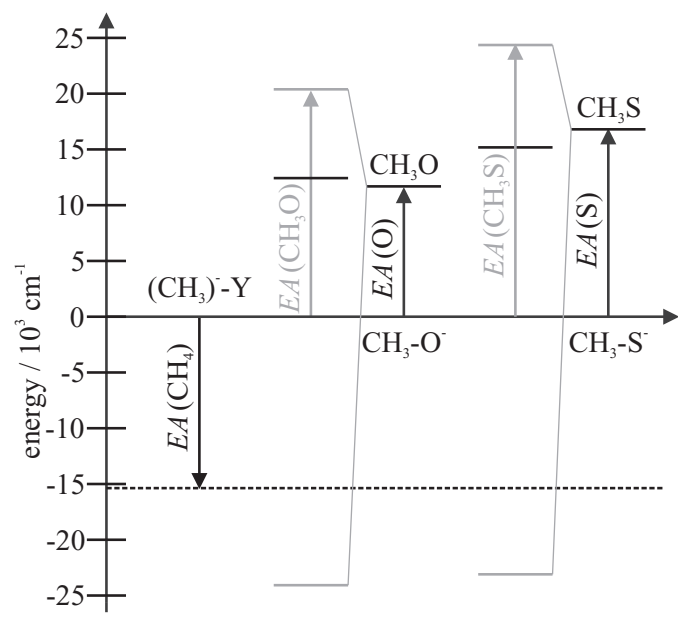

FIG. 7. Schematic energy diagram presenting the electron affinities $E A$ of methane $^{62}$ and of atomic oxygen and sulphur ${ }^{69}$ (black vertical arrows), which are coupled in the excitonic matrix $\mathbf{H}_{\text {exc }}^{\prime}$ (Eq. (10)) by an interaction potential $V_{\mathrm{exc}}=17500 \mathrm{~cm}^{-1}$. The resulting eigenvalues are marked by gray horizontal lines, and the corresponding experimental electron affinities ${ }^{63,64}$ are marked by black horizontal lines.
The model also predicts that $\mathrm{CH}_{3} \mathrm{O}$ and $\mathrm{CH}_{3} \mathrm{~S}$ have an electron hole of predominant $\mathrm{O}$ and $\mathrm{S} \mathrm{p}_{x, y}$ character, respectively.

\section{CONCLUSIONS}

The origin band of the PFI-ZEKE photoelectron spectrum of $\mathrm{CH}_{3} \mathrm{~F}$ has been recorded at a resolution sufficiently high to observe the rotational structure. No spin-orbit splitting could be observed, and the rotational structure of the $\tilde{\mathrm{X}}{ }^{2} \mathrm{E}$ ground state of $\mathrm{CH}_{3} \mathrm{~F}^{+}$was found to follow Hund's angular-momentum coupling case (b). Observations made on the joint effects of spin-orbit and Jahn-Teller interactions in the ${ }^{2} \mathrm{E}$ ground electronic state of the methyl-halide cations, $\mathrm{CH}_{3} \mathrm{O}$, and $\mathrm{CH}_{3} \mathrm{~S}$, have been summarized and differences in the behavior of these systems interpreted in the context of a simple two-state excitonic model. An important element of the interpretation of the general trends observed in these systems was the analysis of the observed spin-orbit splittings in the ground vibronic state, and in particular of the reduction of the effective spin-orbit coupling constant by vibronic effects and configuration mixing, ${ }^{15,16}$ and the correlation of this reduction with the observed strength of the Jahn-Teller effect.

The decreasing strength of the Jahn-Teller effect with increasing spin-orbit coupling constant of the halogen and chalcogen atoms conforms to the overall expectation that a large spin-orbit coupling quenches the Jahn-Teller effect $^{2-4,6-8}$ by forcing the orbital angular momentum of the electron (or electron hole) in the degenerate (e) orbital to couple to the electron spin rather than to the vibrational angular momenta of the degenerate e vibrational modes. The reduction of the spin-orbit coupling constant from its atomic-like value $a(\mathrm{X})$ or $a\left(\mathrm{Y}^{-}\right)$can be decomposed into a purely electronic factor $\zeta_{\mathrm{e}}$ and a Jahn-Teller-induced factor $d_{j, v}$. The reduction factor $\zeta_{\mathrm{e}}$ is attributed to a transfer of the electron hole from the halogen or the chalcogen atom to the pyramidalmethyl side of the molecule. Whereas this transfer is negligible for $\mathrm{CH}_{3} \mathrm{Br}^{+}$and $\mathrm{CH}_{3} \mathrm{I}^{+}\left(\zeta_{\mathrm{e}} \approx 1\right)$ it is almost complete for $\mathrm{CH}_{3} \mathrm{~F}^{+}\left(\zeta_{\mathrm{e}} \approx 0\right)$.

The electron-hole transfer can be described semiquantitatively by a simple excitonic model which considers the pyramidal-methyl and the halogen (chalcogen) sides of the molecules to be separate systems coupled by a charge-transfer coupling term $\mathrm{V}_{\mathrm{exc}}$, the value of which $\left(17500 \mathrm{~cm}^{-1}\right)$ was determined empirically. This excitonic model highlights the importance of two zero-order states of E symmetry, one with the electron-hole density located on the halogen (chalcogen) side of the molecules, the other with the electron-hole density located on the pyramidal-methyl side of the molecules. In this model, the ground states of $\mathrm{CH}_{3} \mathrm{I}^{+}, \mathrm{CH}_{3} \mathrm{Br}^{+}$, and $\mathrm{CH}_{3} \mathrm{~S}$, are well described by the former electronic state, whereas the ground state of $\mathrm{CH}_{3} \mathrm{~F}^{+}$corresponds to the latter. $\mathrm{CH}_{3} \mathrm{Cl}^{+}$and $\mathrm{CH}_{3} \mathrm{O}$ have mixed character. In the early studies of the He I photoelectron spectra of the $\mathrm{CH}_{3} \mathrm{X}$ molecules, Karlsson and co-workers ${ }^{7,8}$ had already recognized the different nature of the ground electronic state of $\mathrm{CH}_{3} \mathrm{~F}^{+}$on the one hand, and of $\mathrm{CH}_{3} \mathrm{Cl}^{+}, \mathrm{CH}_{3} \mathrm{Br}^{+}$, and $\mathrm{CH}_{3} \mathrm{I}^{+}$, on the other.

The main merits of the simple excitonic model presented in this article are its ability to explain qualitatively the trends observed in spectroscopic studies of the methyl-halide cations 
and to provide a simple interpretation of the electronic reduction factor $\zeta_{\mathrm{e}}$. Rather than singling out $\mathrm{CH}_{3} \mathrm{~F}^{+}$as having a different electronic state from the other methyl halides, the model predicts a gradual evolution from $\mathrm{CH}_{3} \mathrm{~F}^{+}$, with the hole predominantly localized on the methyl unit, to $\mathrm{CH}_{3} \mathrm{I}^{+}$, with the hole almost perfectly localized on the iodine atom. $\mathrm{CH}_{3} \mathrm{O}$, in particular, appears to be characterized by a significant delocalization of the electron hole over both sides of the molecule.

The model also enables one to make qualitative predictions of the positions, spin-orbit splittings and Jahn-Teller activity of the first excited electronic state of ${ }^{2} \mathrm{E}$ symmetry, which should show the complementary properties of the ground state.

The simplicity of the model naturally also implies that it will fail to provide a quantitative interpretation of the spectra. The complete neglect of the pseudo-Jahn-Teller coupling to the $\tilde{\mathrm{A}}^{2} \mathrm{~A}_{1}$ state and the assumption of a constant interaction strength $\mathrm{V}_{\mathrm{exc}}=17500 \mathrm{~cm}^{-1}$ represent obvious limitations. We note that charge-separation (charge-transfer) considerations can be used to account for the spin-orbit splitting of other systems, such as $\mathrm{Ni}^{+} \mathrm{X}^{-}(\mathrm{X}=\mathrm{F}, \mathrm{Cl}, \mathrm{Br}, \mathrm{I})$, to cite a recent example. ${ }^{65}$

\section{ACKNOWLEDGMENTS}

We thank Professor H. Köppel (Universität Heidelberg) and Dr. J. T. Hougen (NIST, Gaithersburg) for useful discussions. This work was supported financially by the Swiss National Science Foundation under Project No. 200020-135342.

${ }^{1}$ G. Herzberg, Molecular Spectra and Molecular Structure, Volume III, Electronic Spectra and Electronic Structure of Polyatomic Molecules, 2nd ed. (Krieger, Malabar, 1991).

${ }^{2}$ T. A. Barckholtz and T. A. Miller, Int. Rev. Phys. Chem. 17, 435 (1998).

${ }^{3}$ I. B. Bersuker, The Jahn-Teller Effect (Cambridge University Press, Cambridge, England, 2006).

${ }^{4}$ W. Domcke, S. Mishra, and L. V. Poluyanov, Chem. Phys. 322, 405 (2006).

${ }^{5}$ H. Köppel, L. S. Cederbaum, and S. Mahapatra, in Handbook of HighResolution Spectroscopy, edited by M. Quack and F. Merkt (Wiley, Chichester, 2011), Vol. 3, pp. 1517-1550.

${ }^{6}$ F. S. Ham, Phys. Rev. 138, A1727 (1965).

${ }^{7}$ L. Karlsson, R. Jadrny, L. Mattsson, F. T. Chau, and K. Siegbahn, Phys. Scr. 16, 225 (1977).

${ }^{8}$ F. T. Chau and L. Karlsson, Phys. Scr. 16, 258 (1977).

${ }^{9}$ Y. Endo, S. Saito, and E. Hirota, J. Chem. Phys. 81, 122 (1984).

${ }^{10}$ Y. Endo, S. Saito, and E. Hirota, J. Chem. Phys. 85, 1770 (1986).

${ }^{11}$ J. Liu, M.-W. Chen, D. Melnik, T. A. Miller, Y. Endo, and E. Hirota, J. Chem. Phys. 130, 074303 (2009).

${ }^{12}$ D. Melnik, J. Liu, R. F. Curl, and T. A. Miller, Mol. Phys. 105, 529 (2007).

${ }^{13}$ J. Liu, M.-W. Chen, D. Melnik, J. T. Yi, and T. A. Miller, J. Chem. Phys. 130, 074302 (2009).

${ }^{14}$ D. G. Melnik, J. J. Liu, M. W. Chen, T. A. Miller, and R. F. Curl, J. Chem. Phys. 135, 094310 (2011).

${ }^{15}$ M. Grütter, J. M. Michaud, and F. Merkt, J. Chem. Phys. 134, 054308 (2011).

${ }^{16}$ M. Grütter and F. Merkt, Mol. Phys. 109, 2251 (2011).

${ }^{17}$ Z. Shao, H. Li, S. Zhang, J. Li, Z. Dai, Y. Mo, Y. J. Bae, and M. S. Kim, J. Chem. Phys. 136, 064308 (2012)

${ }^{18}$ S. Mahapatra, V. Vallet, C. Woywood, H. Köppel, and W. Domcke, Chem. Phys. 304, 17 (2004).

${ }^{19}$ S. Mahapatra, V. Vallet, C. Woywood, H. Köppel, and W. Domcke, J. Chem. Phys. 123, 231103 (2005).

${ }^{20} \mathrm{M}$. Grütter, Rotationally resolved spectroscopy of the Jahn-Teller effect in molecular cations, Ph.D thesis, ETH Diss. No. 19756 (2011).
${ }^{21}$ D. S. McClure, J. Chem. Phys. 20, 682 (1952).

${ }^{22}$ J. M. Brown, Mol. Phys. 20, 817 (1971).

${ }^{23}$ J. L. Ragle, I. A. Stenhouse, D. C. Frost, and C. A. McDowell, J. Chem. Phys. 53, 178 (1970).

${ }^{24}$ B. P. Pullen, T. A. Carlson, W. E. Moddeman, G. K. Schweitzer, W. E. Bull, and F. A. Grimm, J. Chem. Phys. 53, 768 (1970).

${ }^{25}$ D. W. Turner, C. Baker, A. D. Baker, and C. R. Brundle, Molecular Photoelectron Spectroscopy: A Handbook of He $584 \AA$ A Spectra (Wiley, New York, 1970).

${ }^{26}$ A. W. Potts, H. J. Lempka, D. G. Streets, and W. C. Price, Philos. Trans. R. Soc. London, Ser. A 268, 59 (1970).

${ }^{27}$ R. N. Dixon, J. N. Murrell, and B. Narayan, Mol. Phys. 20, 611 (1971).

${ }^{28}$ R. Locht, B. Leyh, A. Hoxha, D. Dehareng, H. W. Jochims, and H. Baumgärtel, Chem. Phys. 257, 283 (2000).

${ }^{29}$ R. Locht, B. Leyh, A. Hoxha, D. Dehareng, K. Hottmann, H. W. Jochims, and H. Baumgärtel, Chem. Phys. 272, 293 (2001).

${ }^{30}$ R. Locht, D. Dehareng, K. Hottmann, H. W. Jochims, H. Baumgärtel, and B. Leyh, J. Phys. B 43, 105101 (2010).

${ }^{31}$ A. Strobel, I. Fischer, A. Lochschmidt, K. Müller-Dethlefs, and V. E. Bondybey, J. Phys. Chem. 98, 2024 (1994).

${ }^{32}$ B. Urban and V. E. Bondybey, J. Chem. Phys. 116, 4938 (2002).

${ }^{33}$ P. Wang, X. Xing, K.-C. Lau, H. K. Woo, and C. Y. Ng, J. Chem. Phys. 121, 7049 (2004).

${ }^{34}$ X. Xing, B. Reed, M.-K. Bahng, S.-J. Baek, P. Wang, and C. Y. Ng, J. Chem. Phys. 128, 104306 (2008).

${ }^{35}$ X. Xing, P. Wang, B. Reed, S.-J. Baek, and C. Y. Ng, J. Phys. Chem. A 112, 9277 (2008).

${ }^{36}$ M. Lee, Y. J. Bae, and M. S. Kim, J. Chem. Phys. 128, 044310 (2008).

${ }^{37}$ S. Eden, P. Limao-Vieira, S. V. Hoffmann, and N. J. Mason, Chem. Phys. 331, 232 (2007).

${ }^{38}$ C. L. Lugez, D. Forney, M. E. Jacox, and K. K. Irikura, J. Chem. Phys. 106, 489 (1996).

${ }^{39}$ B. F. Yates, W. J. Bouma, and L. Radom, J. Am. Chem. Soc. 109, 2250 (1987).

${ }^{40}$ J. W. Gauld and L. Radom, J. Phys. Chem. 98, 777 (1994).

${ }^{41}$ U. Höper, P. Botschwina, and H. Köppel, J. Chem. Phys. 112, 4132 (2000).

${ }^{42}$ J. Schmidt-Klügmann, H. Köppel, S. Schmatz, and P. Botschwina, Chem. Phys. Lett. 369, 21 (2003).

${ }^{43}$ F. Merkt, A. Osterwalder, R. Seiler, R. Signorell, H. Palm, H. Schmutz, and R. Gunzinger, J. Phys. B 31, 1705 (1998).

${ }^{44}$ M. S. Child and H. C. Longuet-Higgins, Philos. Trans. R. Soc. London, Ser. A 254, 259 (1961).

${ }^{45}$ A. W. Potts and W. C. Price, Trans. Faraday Soc. 67, 1242 (1971).

${ }^{46}$ R. Signorell and F. Merkt, Mol. Phys. 92, 793 (1997).

${ }^{47}$ A. D. Buckingham, B. J. Orr, and J. M. Sichel, Philos. Trans. R. Soc. London, Ser. A 268, 147 (1970).

${ }^{48}$ S. Willitsch and F. Merkt, Int. J. Mass Spectrom. 245, 14 (2005).

${ }^{49}$ R. G. Tonkyn, R. T. Wiedmann, and M. G. White, J. Chem. Phys. 96, 3696 (1992).

${ }^{50}$ M. S. Child, J. Mol. Spectrosc. 10, 357 (1963).

${ }^{51}$ J. Frenkel, Phys. Rev. 37, 17 (1931).

${ }^{52}$ D. S. McClure, Can. J. Chem. 36, 59 (1958).

${ }^{53}$ A. Müller, F. Talbot, and S. Leutwyler, J. Chem. Phys. 116, 2836 (2002).

${ }^{54}$ A. M. Schulenburg, Ch. Alcaraz, G. Grassi, and F. Merkt, J. Chem. Phys. 125, 104310 (2006).

${ }^{55}$ C. E. Moore, Atomic Energy Levels, NBS Circular 467/1 (National Bureau of Standards, Washington, D.C., 1949).

${ }^{56}$ C. E. Moore, Atomic Energy Levels, NBS Circular 467/2 (National Bureau of Standards, Washington, D.C., 1952).

${ }^{57}$ C. E. Moore, Atomic Energy Levels, NBS Circular 467/3 (National Bureau of Standards, Washington, D.C., 1958).

${ }^{58}$ H. J. Wörner, X. Qian, and F. Merkt, J. Chem. Phys. 126, 144305 (2007).

${ }^{59}$ R. Signorell and F. Merkt, J. Chem. Phys. 110, 2309 (1999).

${ }^{60}$ M. Guerra, Chem. Phys. Lett. 167, 315 (1990).

${ }^{61}$ B. S. Jursic, J. Mol. Struct. 498, 149 (2000).

${ }^{62}$ C.-G. Zhan, J. A. Nichols, and D. A. Dixon, J. Phys. Chem. A 107, 4184 (2003).

${ }^{63}$ P. C. Engelking, G. B. Ellison, and W. C. Lineberger, J. Chem. Phys. 69, 1826 (1978).

${ }^{64}$ R. L. Schwartz, G. E. Davico, and W. C. Lineberger, J. Electron Spectrosc. Relat. Phenom. 108, 163 (2000).

${ }^{65}$ J. T. Hougen, J. Mol. Spectrosc. 267, 23 (2011).

${ }^{66}$ K. Kimura, S. Katsumata, Y. Achiba, T. Yamazaki, and S. Iwata, Handbook of HeI Photoelectron Spectra of Fundamental Organic Molecules: 
Ionization Energies, Ab Initio Assignments, and Valence Electronic Structure for 200 Molecules (Japan scientific Societies, Tokyo, 1981).

${ }^{67}$ B. Ruscic and J. Berkowitz, J. Chem. Phys. 95, 4033 (1991).

${ }^{68}$ B. Ruscic and J. Berkowitz, J. Chem. Phys. 97, 1818 (1992).

${ }^{69}$ C. Blondel, W. Chaibi, C. Delsart, C. Drag, F. Goldfarb, and S. Kröger, Eur. Phys. J. D 33, 335 (2005).
${ }^{70}$ K. P. Huber and G. Herzberg, Molecular Spectra and Molecular Structure, Volume IV, Constants of Diatomic Molecules (Reinhold, New York, 1979).

${ }^{71}$ G. Herzberg, Molecular Spectra and Molecular Structure, Volume II, Infrared and Raman Spectra of Polyatomic Molecules (Reinhold, New York, 1945). 